\title{
Economic Momentum and Currency Returns
}

\author{
Magnus Dahlquist Henrik Hasseltoft*
}

March 27, 2015

\begin{abstract}
Past trends in a broad range of fundamental variables predict currency returns. We document that a trading strategy that goes long currencies in countries with strong economic momentum and short currencies in countries with weak economic momentum exhibits an annualized Sharpe ratio of about one and yields a significant alpha when controlling for standard carry, momentum, and value strategies. The economic momentum strategy subsumes the alpha of carry trades, suggesting that cross-country differences in carry are captured by differences in past economic trends. Moreover, we study investors' expectations of fundamental variables and find the expectations to be extrapolative but negatively related to the portfolio weights, which rank economic trends across countries.
\end{abstract}

Keywords: Carry trade, extrapolation, foreign exchange rates, predictability, surveys, trend following, trends.

JEL Classification Numbers: F31, G12, G15.

\footnotetext{
${ }^{*}$ We thank Ricardo Lopez Aliouchkin and Vasilij Dedes for research assistance. We have benefited from the comments of seminar participants at the London Business School. Dahlquist: Stockholm School of Economics and CEPR; e-mail: magnus.dahlquist@hhs.se. Hasseltoft: University of Zurich and the Swiss Finance Institute; e-mail: henrik.hasseltoft@bf.uzh.ch.
} 


\section{Introduction}

Present-value models suggest that the exchange rate can be written as a function of current and expected fundamentals. However, ever since the seminal work of Meese and Rogoff (1983), researchers have struggled to find support for these models, as fundamentals have problems predicting exchange rates out of sample. Rather than using macro fundamentals, researchers have documented cross-sectional and time-series predictability of exchange rates in the form of carry, momentum, and value strategies. However, it is still widely debated what economic risks, if any, these strategies represent. ${ }^{1}$ In addition, as expectations of fundamentals arguably matter for exchange rates (e.g., Engel and West, 2005; Engel et al., 2007; Sarno and Schmeling, 2014), it becomes important to understand how investors actually form expectations. While it has been documented that investors' expectations of returns on financial assets are extrapolative, there is less empirical evidence as to whether this also holds true for investors' expectations of fundamentals. ${ }^{2}$

We contribute to the literature in three ways. First, we document that past trends, measured over 1-60 months, in a broad range of macro fundamentals predict currency returns. A momentum strategy that goes long currencies in countries with relatively strong economic momentum and short currencies in countries with relatively weak economic momentum ex-

\footnotetext{
${ }^{1}$ The literature on the carry trade and its potential determinants is vast. For example, Lustig and Verdelhan (2007) explain deviations from the uncovered interest-rate parity with reference to aggregate consumption risk. Brunnermeier et al. (2009), Chernov et al. (2014), Daniel et al. (2014), Farhi et al. (2014), Jurek (2014), and Lettau et al. (2014) relate the carry trade to crash and downside risk. Burnside et al. (2011) argue that carry-trade profits reflect a peso problem. Lustig et al. (2011) identify a carry-trade risk factor. Menkhoff et al. (2012b) find that carry-trade profits are compensation for global foreign exchange rate volatility risk. Engel (2014) surveys the literature on carry trades and the determinants of exchange rates.

${ }^{2}$ While the findings of Malmendier and Nagel (2014) suggest that individuals' inflation expectations reflect extrapolative behavior, to our knowledge no study documents whether this also holds true for a broad range of economic variables and countries. Greenwood and Shleifer (2014) and Koijen et al.(2015) document that investors' expectations of returns on financial assets are extrapolative. Fuster et al. (2010) survey the literature on extrapolation. There is also a growing theoretical literature that explores the implications of investors having extrapolative expectations of fundamentals (e.g., Fuster et al., 2011; Choi and Mertens, 2013; Hirshleifer et al., 2015).
} 
hibits an annualized Sharpe ratio of about one over the 1976-2014 period, and delivers a statistically significant alpha when controlling for common currency strategies. That is, currencies whose countries have experienced relatively strong (weak) economic trends in the past are associated with high (low) expected returns. Second, we find that momentum returns based on fundamentals subsume the alpha of carry-trade strategies. This suggests that cross-country differences in carry are captured by differences in past economic trends, where countries that rank high (low) in terms of carry are countries that have experienced strong (weak) economic growth, inflation, and trends in interest rates in the past. Third, we study the determinants of investors' expectations of macro fundamentals across a broad range of economic variables and countries and find that expectations of all variables load positively on recent economic trends, suggesting uniformly extrapolative expectations. However, investor expectations are negatively related to the portfolio weights, which rank the strength of economic trends across countries.

We measure trends in eight fundamental variables: one-month interest rates, yield spreads, ten-year interest rates, inflation, trade balances, industrial production, retail sales, and unemployment. We base the main results on two simple and intuitive measures of economic trends, namely, past changes and the statistical significance of linear time-trend regressions, and measure trends over the past 1-60 months. We define the fundamental variables such that increases in the variables are associated with positive economic growth. ${ }^{3}$ We form trading strategies for each variable and trend horizon and for a combination of trends. We find that the cross-section of past economic trends significantly predicts excess returns and exchange-rate changes up to a horizon of twelve months. While past trends in fundamentals over the short, intermediate, and long horizons all contain independent information about

\footnotetext{
${ }^{3}$ To be more specific, we consider increasing interest rates, flatter yield spreads, positive inflation, increasing trade surpluses, positive growth in industrial production, positive growth in retail sales, and lower unemployment by considering the inverse of unemployment. We find that the variables, except for trade balance, are empirically positively related to the growth in industrial production.
} 
expected returns, the strongest contribution to performance comes from long-term trends over the past three to five years. Long-term trends in fundamentals also most strongly capture the carry-trade alpha.

While we apply the trend measures to fundamentals, Moskowitz et al. (2012) and Baltas and Kosowski (2015) apply them to futures prices across asset classes and document high Sharpe ratios from strategies based on time-series momentum and trend following. That we apply the same trend measures but to fundamentals implies that the investment strategy can be viewed as a cross-sectional trend-following strategy based on fundamentals. Interestingly, neither traditional cross-sectional nor time-series exchange rate momentum strategies can explain the returns of the trading strategy, suggesting that price and fundamental momentum strategies represent distinct strategies.

Our findings are related to those of Ang and Chen (2010), who predict currency returns from monthly changes in interest rates and yield spreads. They document Sharpe ratios of approximately 0.50 when using changes in interest rates but a Sharpe ratio of near zero when using changes in yield spreads. Importantly, they find monthly changes in interest rates and yield spreads to be unrelated to the carry trade. However, we find that when using long-term changes for up to five years, Sharpe ratios improve substantially and interest-rate changes become significant determinants of carry-trade profits.

Our findings imply that fundamentals do matter for exchange rates but raise the question of why currencies whose countries have experienced positive economic momentum would be subject to high expected returns. If the results are to be mapped into a present-value framework, they imply that past macro trends capture current expectations of future macro fundamentals. In addition, the fact that the alpha from carry trades is subsumed by the strategy raises the question of why carry and past economic trends should be related. Several possible explanations could be considered, but one particular explanation that seems applicable is that of monetary policy and the role of Taylor (1993) rules. Provided that 
the monetary authorities of a country adhere to a Taylor-type rule, then strong economic conditions and rising inflation in the past likely induced a tightening of monetary policy. In this case, countries with currently high (low) carry likely experienced positive (negative) past trends in economic fundamentals. Cross-sectional carry could therefore be captured by relative trends in fundamentals. However, we cannot rule out other explanations. It is worth noting that, while the economic momentum strategy captures the alphas of carry trades, carry trades cannot fully explain the returns of the economic momentum strategy. Hence, investing according to past trends in fundamentals seems to represent an additional source of returns. The exact origin of these returns remains an open question.

A recent and growing literature has documented that investors' expectations of returns on various financial assets are extrapolative (e.g., Greenwood and Shleifer, 2013; Barberis et al., 2014; Koijen et al., 2015), but there is less empirical evidence as to whether this is also true for expectations of fundamentals. To shed some light on this issue, we study how investors' expectations of fundamentals depend on past changes in the variables they forecast. We use quarterly survey expectations from the World Economic Survey to measure investors' expectations over the next six months across a large number of countries. Regressing investors' expectations on recent changes in fundamental variables yields positive coefficients across all variables, suggesting that expectations of fundamentals are uniformly extrapolative. However, regressing surveys on the portfolio weights, which measure the ranking of economic trends across countries, yields significant and negative coefficients. Hence, recent economic trends within a country and the ranking of trends across countries seem to relate differently to investors' expectations.

In addition, we document that investors' expectations of the future appreciation of their currencies are negatively related to the model-implied expected returns. That is, when the trading strategy predicts positive returns on a currency, investors expect a depreciation of the currency. Consistent with this, we find that investing according to investors' views of the 
future strength of their currency yields a negative performance. This is consistent with recent evidence presented by Koijen et al. (2015). We therefore also consider a trading strategy that invests according to investor's expectations of fundamentals. We form a portfolio that goes long the currencies of countries for which investors expect an increase in the variables, which in the data tend to be associated with good economic conditions, and short the currencies of countries for which the expectations are negative. We find that such strategies also yield negative Sharpe ratios. That is, investing in countries for which investors expect tighter monetary policy, stronger growth, and higher inflation yields negative performance.

Our finding that past trends in a country's trade balance predict currency returns is related to that of Gourinchas and Rey (2007), who demonstrate that a country's external imbalance must predict either future net export growth or future returns on the country's foreign asset portfolio (or both). A key determinant of the return on the foreign asset portfolio is the future evolution of the country's currency, implying predictability of exchange rates. Indeed, Gourinchas and Rey (2007) document that the deviation of a country's trade surplus from its trend predicts the appreciation of its currency. ${ }^{4}$ Rather than using the deviation of the trade balance from its trend, we find that the trend itself predicts currency returns. We also check whether a strategy based on deviations from the trend generates positive returns and find that it generates a positive Sharpe ratio, supporting earlier studies.

Section 2 describes the data while section 3 describes how we measure economic momentum from trends in fundamental variables and how we form portfolios. Section 4 presents and discusses the performance of the economic momentum strategy and section 5 studies how investors' expectations of fundamentals relate to past trends in fundamentals. Section 6 concludes.

\footnotetext{
${ }^{4}$ Building on these findings, Della Corte et al. (2012) take a portfolio approach and find that an investor who conditions on the cyclical external imbalance of a country when investing in foreign exchange experiences large utility gains. Della Corte et al. (2014) consider a risk factor based on global imbalances to capture cross-sectional variation in currency returns.
} 


\section{Data}

\section{$2.1 \quad$ Exchange rates}

We retrieve daily data on spot and one-month forward exchange rates from Datastream for the period from January 1976 to May 2014 for nineteen countries-i.e., Australia, Austria, Belgium, Canada, Denmark, France, Germany, Ireland, Italy, Japan, the Netherlands, New Zealand, Norway, Portugal, South Africa, Spain, Sweden, Switzerland, and the UK-as well as the Eurozone. All twenty currencies are expressed in US dollars (USD) per unit of foreign currency. An increase in the exchange rate of currency $c$ at time $t, S_{c, t}$, implies appreciation of the foreign currency and depreciation of the USD. As one-month interbank rates are not available for all countries during this period, we compute implied one-month rates using covered interest-rate parity using spot and forward exchange rates and the onemonth interbank US rate. We assume the USD to be the home currency, the excess return on investing in foreign currency $c$ via a forward contract, $F_{c, t}$, being denoted $R_{c, t+1}=\left(S_{c, t+1}-\right.$ $\left.F_{c, t}\right) / F_{c, t}$. Currencies now in the Eurozone are used only until 31 December 1998, after which the Euro is used. We also consider a smaller subset of currencies comprising the G10 currencies, representing Australia, Canada, the Eurozone, Japan, New Zealand, Norway, Sweden, Switzerland, and the UK. Results pertaining to G10 currencies are reported in an online appendix.

\section{$2.2 \quad$ Fundamental variables}

We collect data on eight fundamental variables: one-month interbank rates, yield spreads, ten-year interest rates, inflation, trade balances, industrial production, retail sales, and unemployment. One-month interbank rates are computed using covered interest-rate parity as described above. Remaining data are collected from the statistical database of the OECD. The trade balance of a country is constructed by retrieving exports and imports 
of goods, measured in USD, and then defining the trade-balance measure as (Exports - Imports)/ (Exports + Imports), capturing the trade imbalance of goods as a proportion of total goods traded. ${ }^{5}$ Monthly growth rates in industrial production and retail sales together with monthly inflation are also collected and used to construct production, sales, and consumer price indices. Unemployment data are collected; we use the inverse of unemployment so that an increase in the variable corresponds to good economic conditions. Long-term interest rates, also available from the OECD, predominantly reflect ten-year nominal government bonds. We define yield spreads as short rates minus long rates, meaning that an increase in the variable reflects a flattening of the yield curve, which is typically associated with good economic conditions. Hence, the variables are constructed such that increases in the variables are positively related to economic growth and consequently correspond to higher trade surpluses, higher growth, higher inflation, rising interest rates, and a flattening of the yield curve. We verify that the variables are indeed positively related to economic growth, though the trade balance has a negative but insignificant coefficient. Results of these panel regressions are reported in an online appendix. All data cover the period from January 1976 to May 2014. The short-rate data comprise daily observations while the remaining data comprise monthly observations.

\subsection{Surveys}

We obtain quarterly survey expectations from the World Economic Survey (WES), which can be downloaded from Datastream. Economists in over 120 countries are polled on their expectations of future macro variables, exchange rates, interest rates, and stock prices for the next six months. The participants work in the countries in which the survey is administered and represent a broad range of organizations such as banks, insurance companies, research

\footnotetext{
${ }^{5}$ Alternatively, the net exports can be normalized by the level of GDP, though the results achieved are similar.
} 
institutions, the IMF, the OECD, and the media. Survey participants are asked whether a particular variable will be higher, the same, or lower six months from the day of the survey. The response is then coded 9 for higher, 5 for the same, and 1 for lower. The final score is the average of individual responses. Data availability depends on the particular variable and starts in 1989. Responses are collected during the first month of each quarter and are published via a press release in the second month of the quarter. Recently, Koijen et al. (2015) used these surveys in a study of expected returns and asset pricing puzzles. Stangl (2007) and Kudymowa et al. (2013) present more detailed information about the surveys.

We focus on surveys that can be directly mapped to the fundamental variables. We collect quarterly survey responses regarding expected short rates, yield spreads, long rates, inflation, trade balance, and economic activity. Yield spread expectations are not directly obtainable, so we construct a proxy by taking the difference between short-rate and long-rate expectations. Hence, an increase in the yield-spread variable reflects expectations of a flatter yield curve. We also collect survey expectations of the future value of the local currency. As the survey asks about the future value of the USD relative to the local currency, we take the inverse of the survey score to make a higher score imply expected strengthening of the local currency and weakening of the USD. Surveys regarding short rates, trade balance, economic conditions, and foreign exchange are available from Q1 1989, inflation surveys from Q3 1991, and long-rates from Q2 1998.

\section{Economic momentum and portfolio construction}

The main results are based on two ways of measuring trends, namely, changes (or log changes) in variables and the significance of linear time trends. The construction of the trend measures is kept simple to minimize any data-mining concerns. For robustness, we have also considered trend measures based on moving averages and quadratic time-trend regressions, with very 
similar results. The main results are based on all twenty currencies, but we also report results for the G10 countries in an online appendix. The objective is to measure various trend frequencies and avoid arbitrary lookback periods. We consider lookback periods of 1-60 months, where the minimum lookback period used for each variable depends on the trend measure employed and whether data for that particular variable are observed daily or monthly. As the data frequency differs among the variables and we would like to use as much data as possible, the construction of the trend measures differs slightly across variables while remaining conceptually the same. All trend measures are computed at the end of each month when portfolio rebalancing occurs.

\subsection{Momentum in short rates}

Data on one-month short rates consist of daily observations with continuously compounded short rates being denoted $r_{t}$. The first trend measure is constructed as the changes in short rates for each country over the last $h=1: 60$ months, normalized by the volatility of rate changes:

$$
\frac{r_{t}-r_{t-h}}{\sigma_{r, t}}
$$

where $\sigma_{r, t}$ measures the volatility of daily interest-rate changes over the lookback period and is computed using an exponentially weighted moving average with a decay parameter of 0.94 . The second trend measure is based on a linear time-trend regression in which at each time $t$ we estimate a linear time trend in $r_{t}$ for each lookback period of $h=1: 60$ months:

$$
r_{\tau}=\alpha_{h, t}+\beta_{h, t} \tau+\epsilon_{\tau}
$$

where $\tau=t-h \times 21, \ldots, t$ and $h \times 21$ denotes the number of trading days over which the regression is estimated. The investment signal is based on the strength of time trends, measured by the $t$-statistic of $\beta_{h, t}$, where standard errors are computed using the Newey 
and West (1987) procedure. ${ }^{6}$ Note that the regression coefficients depend on both lookback period, $h$, and time, $t$. This means that we are not fitting a global regression line but instead a series of local regression lines each month, spanning a range of lookback periods.

\subsection{Momentum in macro variables}

Unlike short rates, for which we have daily observations, the remaining data on ten-year yields, yield spreads, trade balances, consumer price indices, industrial production indices, retail sales indices, and unemployment are monthly, so the trend construction is slightly different. The first trend measure based on changes is constructed as changes over $h=1: 60$ months, $X_{t}-X_{t-h}$, where $X_{t}$ denotes the particular variable in levels or $\operatorname{logs}^{7}$ The second trend measure is again based on the statistical significance of a linear time-trend regression but now using monthly data. To guarantee a reasonable minimum number of observations, we consider lookback periods of $24-60$ months. We run the following regression:

$$
X_{\tau}=\alpha_{h, t}+\beta_{h, t} \tau+\epsilon_{\tau},
$$

where $\tau=t-h, \ldots, t$. The investment signal is based on the strength of the time trend, measured by the $t$-statistic of $\beta_{h, t}$, standard errors being computed using the Newey and West (1987) procedure. ${ }^{8}$ Again, note that the regression coefficients vary with both lookback horizon, $h$, and time, $t$.

\footnotetext{
${ }^{6}$ To ensure consistency of the variance-covariance matrix, the number of lags used in the procedure should grow with the number of observations. For parsimonious reasons, we set the number of lags equal to $(h \times 21)^{1 / 3}$. Selecting a different number of lags has a small impact on our results. See, for example, Andrews (1991) and Newey and West (1994) for optimal lag-selection procedures.

${ }^{7} \mathrm{Log}$ changes are used for consumer price indices, industrial production indices, retail sales indices, and unemployment. Actual changes are used for trade balances, yield spreads, and ten-year interest rates. We do not normalize these changes by volatility because the observations are monthly, leading to imprecise volatility estimates.

${ }^{8}$ The results are based on using three-month-lagged information for non-interest rate variables when forming portfolios to guarantee that investors had access to relevant macro information when rebalancing and to address the fact that macro data are often published with a lag. However, such information lagging has a small impact on the final results.
} 


\subsection{Discussion of momentum measures}

It is common in economics to decompose economic variables into trend and cyclical components, the trend component being viewed as a deterministic function of time and the cyclical component as a stationary process evolving around the trend. We are interested in the trend component and estimate it via deterministic time-trend regressions, measured over the past 1-60 months. The investment strategy then relates the strength of past trends of various variables to those in other countries. While it is common in economics to estimate time trends over decades of data, our focus is different. We instead view trends as does the literature on time-series momentum and trend following of financial prices.

A significant slope coefficient in a time-trend regression naturally means that the variable is non-stationary in the mean. However, we do not use the non-stationary variable itself for predicting returns but instead use the statistical significance of the slope coefficient in the form of simple $t$-statistics. Rather than being non-stationary, the $t$-statistics evolve over time in a stationary manner, capturing periods of positive and negative economic momentum. The online appendix illustrates the time trends, comparing the 60-month time trend in industrial production in Canada and the UK. The example illustrates how the $t$-statistics change over time. Naturally, $t$-statistics of shorter-term time trends oscillate more strongly over time. The example also illustrates how the strategy assigns larger portfolio weights to countries where economic momentum is strong than to countries with weak economic momentum.

\subsection{Construction of momentum portfolios}

Having described how we construct the trend measures, we now describe how portfolios are formed. Three dimensions must be considered when constructing portfolios, namely, the fundamental variable, the trend measure, and the lookback period. We construct a strategy for each variable, for each of the two trend measures, and for each lookback period. For 
example, for short rates, there are 60 lookback periods (1-60 months) using changes and when running time-trend regressions, resulting in 120 sub-strategies. For the other variables for which we employ monthly data, there are 60 lookback periods using changes but only $60-24+1$ lookback periods for the time-trend regressions, resulting in 97 sub-strategies. In total, 799 sub-strategies are constructed. We later aggregate these sub-strategies based on type of fundamental variable and the trend horizon. We also consider a strategy that diversifies across all available sub-strategies.

At the end of each month, currencies are ranked according to the strength of each trend measure for a particular variable and horizon. We weight currencies according to their crosssectionally ranked signal, similar to the method used by Asness et al. (2013) and Koijen et al. (2013). Every month, the rank-based weight for currency $c$ using variable $v$ for trend measure $i$ and for lookback horizon $h$ at time $t$ is defined as:

$$
w_{c, v, i, h, t}=\kappa_{t}\left[\operatorname{rank}\left(z_{c, v, i, h, t}\right)-\frac{1}{C_{t}} \sum_{c=1}^{C_{t}} \operatorname{rank}\left(z_{c, v, i, h, t}\right)\right]
$$

where $z_{c, v, i, h, t}$ denotes the investment signal for currency $c$ using variable $v$ and trend measure $i$ for lookback horizon $h$ at time $t, C_{t}$ denotes the total number of available currencies at time $t$, and $\kappa_{t}$ denotes a scaling factor ensuring that the strategy invests one dollar on the long side and one dollar on the short side, making it dollar neutral. ${ }^{9}$ The portfolio return at time $t+1$ for variable $v$ using trend measure $i$ and lookback horizon $h$ is therefore:

$$
R_{v, i, h, t+1}=\sum_{c=1}^{C_{t}} w_{c, v, i, h, t} R_{c, t+1}
$$

Hence, these returns for each sub-strategy have been scaled to invest one dollar on the long side and one dollar on the short side. Using the sub-strategies, we form aggregate portfolios

\footnotetext{
${ }^{9}$ We consider additional weighting schemes and find that results are similar if we instead sort currencies into top and bottom quintiles or quartiles based on trends.
} 
across variables, trend measures, and lookback periods. As the volatility of each sub-strategy is different, we weigh each sub-strategy by the inverse of its volatility over the past three years and scale the weights such that they sum to one. We then scale the weights of this aggregate portfolio by a factor of $5 \%$ divided by the past realized volatility of the aggregate strategy, which represents a simple method of volatility timing (e.g., Fleming et al., 2001; Kirby and Ostdiek, 2012). We later report results of individual portfolios for each of the eight variables, aggregate portfolios using short-, medium-, or long-term trends, aggregate portfolios using only changes or time trends, and finally a combined trend portfolio ("combo") covering all sub-strategies.

\subsection{Construction of benchmark strategies}

We construct a number of portfolios based on well-established currency strategies. We use these additional strategies as benchmarks when evaluating the performance of the trend strategies. Closely following the existing literature, we construct benchmark strategies in the forms of carry, momentum, value, dollar-carry, and long-only strategies. We employ two weighting schemes for the first three strategies and one weighting scheme for the last two, for a total of eight benchmark strategies. All strategies use end-of-month rebalancing.

The carry portfolio is constructed by sorting countries according to their forward premia. Covered interest-rate parity implies that $F_{c, t} / S_{c, t}=\left(1+i_{t}\right) /\left(1+i_{c, t}\right)$, where $i_{t}$ and $i_{c, t}$ denote the domestic and foreign one-month interest rates, respectively. The carry trade is implemented by going long currencies that trade at a forward discount $\left(F_{c, t}<S_{c, t}, i_{c, t}>i_{t}\right)$ and short currencies that trade at a forward premium $\left(F_{c, t}>S_{c, t}, i_{c, t}<i_{t}\right)$.

We rank currencies each month according to their forward premia and build portfolios using two weighting schemes. The first scheme uses rank-based weighting similar to that 
described previously:

$$
w_{c, t}=\kappa_{t}\left[\operatorname{rank}\left(S_{c, t}-F_{c, t}\right)-\frac{1}{C_{t}} \sum_{c=1}^{C_{t}} \operatorname{rank}\left(S_{c, t}-F_{c, t}\right)\right]
$$

where the long and short side of the strategy both have one USD invested, implying a zerocost and USD-neutral portfolio. We denote this weighting scheme "CS," for cross-sectional ranking. The second set of weights, $w_{c, t}$, for currency $c$ at time $t$ is defined as:

$$
w_{c, t}=\operatorname{sign}\left(S_{c, t}-F_{c, t}\right) / C_{t} .
$$

These weights go long (short) currencies with forward discounts (premiums) and assign equal weights to all currencies. One US dollar is spread out over all positions, meaning that the weights do not necessarily sum to zero, implying that the strategy is not necessarily USD neutral. For example, if all currencies trade at a forward discount to the USD, the strategy is long all foreign currencies and therefore short one USD. We denote this weighting scheme "TS," highlighting that the weight of a currency is determined solely by its own time series of forward discounts/premia. ${ }^{10}$

Momentum and value portfolios are constructed similar to how Asness et al. (2013) construct portfolios. ${ }^{11}$ The momentum portfolio ranks currencies according to their returns over the past twelve months. The strategy then goes long currencies with high past returns and short currencies with low past returns. The value portfolio sorts currencies according to the negative of the log change in real exchange rates over the past 60 months. More specifically,

\footnotetext{
${ }^{10}$ Hassan and Mano (2014) distinguish between currency strategies that form portfolio weights based on the cross-sectional rank of forward discounts as opposed to the time series of each currency's forward discount. They argue that these strategies represent different anomalies in the data and require different risk-based explanations.

${ }^{11}$ Momentum and value strategies for currencies are also studied in Menkhoff et al. (2012a) and in Menkhoff et al. (2015). Asness et al. (2013) find that combinations of value and momentum strategies provide diversification benefits. Moreover, Jordà and Taylor (2012) document diversification benefits of combining carry trades with a value-based measure of exchange rates, and Barroso and Santa-Clara (2013) find large benefits of diversifying across carry, momentum, and value strategies.
} 
the value signal for currency $c$ in month $t$ is defined as $\left(\pi_{t-60: t}-\pi_{c, t-60: t}\right)-\Delta s_{c, t-60: t}$, where $\pi_{t-60: t}$ denotes US log inflation over the last 60 months, $\pi_{c, t-60: t}$ denotes the corresponding foreign $\log$ inflation, and $\Delta s_{c, t-60: t}$ denotes the $\log$ depreciation of the USD over the last 60 months. The strategy then goes long high-value currencies and short low-value currencies. We construct momentum and value portfolios using both CS and TS weights.

Following Lustig et al. (2014), we also construct a dollar carry trade. The strategy goes long (short) all foreign currencies if the average foreign short-term interest rate is higher (lower) than the US interest rate; differently stated, the strategy goes long (short) all foreign currencies if the average forward premium is negative (positive). Hence, this strategy is not dollar neutral but is either long or short one USD. All foreign currencies receive equal weights in the portfolio. Finally, we also construct a long-only portfolio that is simply long an equal-weighted portfolio of all foreign currencies versus the USD. This corresponds to the average excess-return portfolio in Lustig et al. (2011).

\section{Performance}

We now present and discuss the performance of the trend strategies. We report performance statistics for trend strategies based on each separate fundamental variable, for strategies based on short-, medium-, and long-term trends and for strategies diversified across variables and horizons. We then relate the trend strategies to the various benchmark strategies, run predictive panel regressions, and specifically relate the trend strategies to the well-known carry strategy.

\subsection{Performance of momentum strategies}

We construct portfolios for each of the eight variables, for each trend measure, and for each applicable lookback period. Figures 1 and 2 report annualized Sharpe ratios for all sub- 
strategies based on changes and time trends, respectively. The figures show that virtually all sub-strategies, except for long-term time trends in unemployment, have positive Sharpe ratios. The Sharpe ratios not only differ across variables but also across lookback periods for each variable and across trend measures. The return correlations across variables, trend measures, and horizons are less than perfect. Consequently, an investor can achieve diversification benefits by forming an aggregate portfolio of sub-strategies. Combining investment signals in this manner is analogous to diversifying across predictive variables when making forecasts, which, for example, Wright (2008) and Rapach and Zhou (2013) have shown improves out-of-sample forecasting performance.

We construct such aggregate portfolios for each of the eight fundamental variables and report the performance statistics in Table 1. Trend strategies based on all variables are profitable, having Sharpe ratios ranging from 0.28 for retail sales to 0.89 for short rates. ${ }^{12}$ The Sortino ratios are defined as average excess return divided by downside volatility, which penalizes strategies with large negative skewness. The strategies display moderate skewness except for the inflation-based strategy, which has a negative skewness of 0.76 . The hit ratios refer to the proportion of all months with positive returns and average approximately $60 \%$. The worst drawdowns tend to occur with strategies based on measures of economic activity. We also report the duration in months of the worst drawdown for each strategy and find them to range from 22 months for short rates to 232 months for retail sales. The construction of each strategy employs leverage of approximately 2.5, on average. The cumulative returns of each of the eight portfolios are plotted in Figure 3. The correlations of returns between the eight strategies, reported in the online appendix, are rather low, with an average pairwise correlation of approximately 0.2. Strategies based on interest rates exhibit rather

\footnotetext{
${ }^{12}$ More specifically for the interest-rates variables, we document Sharpe ratios of 0.89, 0.80, and 0.54 for short rates, yield spreads, and long rates, respectively. This can be compared to Ang and Chen (2010) who for the same variables but using only monthly changes document Sharpe ratios of $0.44,-0.17$, and 0.55 . Hence, the investment performance seems to improve substantially when considering longer-term changes in interest rates and yield spreads.
} 
high correlations among themselves, while the other correlations are substantially lower.

Building on the low correlations across variables and strategies, we construct a trend combo that combines all available sub-strategies. The last column in Table 1 reports the performance of this strategy, where the achieved diversification benefits are evident from the higher Sharpe and Sortino ratios of 1.10 and 1.89, respectively, and the higher hit ratio of $68 \%$. The cumulative return of this portfolio is also plotted in Figure 3. Analyzing the strategy's worst and best months, we find the three worst months to be March 1995 (6.64\%), September $2008(-4.35 \%)$, and July $1999(-4.30 \%)$ and the three best months to be June 1988 (4.87\%), December 2001 (5.08\%), and June 1981 (5.35\%). Importantly, a trend combo that excludes the interest-rate variables yields a Sharpe ratio of 0.85 , as reported in the online appendix.

We also study how the performance depends on the lookback period and trend measure used. First, we construct three combos with short-, medium-, and long-term trends, measured over 1-12 months, 13-36 months, and 37-60 months, respectively. Table 2 reports the results, showing that investment performance improves with the length of the trend used. The short-term trend portfolio has an annualized Sharpe ratio of 0.81 versus 1.06 for the long-term trend portfolio. The long-term portfolio exhibits smaller drawdowns that are substantially shorter in duration. Hence, the strongest return contribution to the trend strategy seems to come from long-term trends in fundamentals. Second, we construct two portfolios that use changes in variables and the significance of time trends, respectively. Table 2 shows that both measures produce similar performance with Sharpe ratios of one. That the trend strategies generate positive returns indicates that the strategies capture cross-sectional predictability of currency returns. We run predictive panel regressions using the next period's currency return as the dependent variable and standardized portfolio weights for different 
trend strategies as independent variables:

$$
R_{c, t+1}=a_{t}+b \tilde{w}_{c, t}+\epsilon_{c, t+1}
$$

where $R_{c, t+1}$ denotes the monthly excess return for currency $c$ at time $t+1, \tilde{w}_{c, t}$ denotes the standardized portfolio weight for currency $c$ at time $t$, and $a_{t}$ denotes time fixed effects. Weights for aggregate strategies are constructed by weighting each sub-strategy by the inverse of its past volatility and scaling the weights such that they sum to one. Weights are then scaled by a factor of $5 \%$ divided by the past volatility of the aggregate strategy. Finally, weights are cross-sectionally standardized in each month. We predict returns using portfolio weights for trend strategies based on interest rates, inflation, trade balance, economic activity, and the trend combo. Table 3 reports results indicating that all trend strategies predict future currency returns with coefficients being highly statistically significant. For example, a coefficient of 0.21 for the trend combo means that a portfolio weight one standard deviation above the mean predicts a positive currency return of $0.21 \%$ the next month. An increase in the portfolio weight can also be interpreted as an increase in a currency's portfolio rank. In this case, a one-standard-deviation-increase in portfolio weight corresponds to a four-step increase in ranking. There are on average 14 currencies in the portfolio at each time $t$, so, for example, moving from rank 4 to rank 12 predicts a positive return of $0.42 \%$ the next month. The last column indicates that all trend strategies predict returns significantly when considered jointly.

\subsection{Economic momentum versus benchmark strategies}

Having established that investing according to past trends in fundamentals yields high riskadjusted returns, the question arises as to whether the economic momentum strategy is simply a repackaged version of existing currency strategies. We answer this question by 
relating the returns on trend strategies to those on standard carry, momentum, value, dollarcarry, and long-only portfolios. We construct the benchmark strategies as described in Section 3.5 and report their performance statistics in Table 4. All strategies except the time-series value and long-only portfolios have high Sharpe ratios. Most of the strategies have negative skewness and rather large and extended drawdowns.

Next we study how well the benchmark strategies can explain the returns of the trend combo. We run contemporaneous time-series regressions using trend-combo returns as the dependent variable and the returns of various benchmark strategies as independent variables. Table 5 reports the results of each regression specification. First, we regress the returns of the trend combo on the dollar-carry and long-only strategies together with cross-sectional-carry, momentum, and value strategies. The resulting alpha is highly significant, both statistically and economically. The annualized alpha of $3.22 \%$ represents $52 \%$ of the average return of the trend combo (i.e., less than half of the average trend returns are explained by existing currency portfolios). The positive and significant coefficient for carry returns suggests that a portion of the trend returns reflects cross-sectional differences in carry. Second, we instead consider time-series-carry, momentum, and value strategies as benchmarks. The estimated alpha is larger than before and the coefficient for carry is again positive and significant. Finally, we regress trend returns on proxies for volatility and funding risks in the forms of changes in FX volatility, the VIX index, and the TED spread. The coefficient for the TED spread is negative and significant, suggesting that worsening funding conditions are associated with poor returns of the trend combo.

Finally, we turn to predictive regressions. We begin by predicting currency returns one month ahead using portfolio weights for the cross-sectional carry, momentum, and value strategies as well as the trend combo. Portfolio weights are standardized in each month as described earlier. Specifications I-III in Table 6 indicate that the three benchmark strategies positively predict returns with highly significant coefficients. However, the magnitudes of 
the coefficients and the $R$-squared values are smaller than those of the trend combo. Specification $\mathrm{V}$ includes all benchmark strategies jointly, with coefficients remaining significant. Specification VI includes the benchmark strategies and the trend combo jointly. The combo drives out the significance of the carry portfolio, leaving only the momentum and value portfolios significant. These results suggest that the trend combo captures the predictive power of the carry portfolio while the momentum and value strategies seem to represent distinct strategies.

We also predict multi-period currency returns for up to twelve months. The regressions include the same three benchmark strategies as used for monthly returns together with the trend combo. Table 7 reports the results. The coefficients of the trend combo remain high and strongly statistically significant for all forecasting horizons. In contrast, the carry strategy has no predictive power while the momentum portfolio loses its predictive power over longer horizons. Like the trend combo, the value strategy possesses significant forecasting power for all forecasting horizons. The $R$-squared increases from $1.51 \%$ for one-month horizons to $11.60 \%$ for twelve-month horizons. We report predictability of results in terms of foreign currency appreciation or dollar depreciation, i.e., $\left(S_{c, t+1}-S_{c, t}\right) / S_{c, t}$, in Table 8. The trend combo retains its predictive power with positive and significant coefficients, albeit with smaller coefficients.

\subsection{Economic momentum and the carry trade}

The last sub-section demonstrated that the trend combo drives out the significance of the carry strategy when predicting currency returns. This suggests that the trend combo captures the nature of the carry trade. We investigate this further by regressing carry-trade returns on the returns of the remaining benchmark strategies and the various trend strategies. Table 9 reports the results. Specification I reports the results of including only the additional benchmark strategies as independent variables. The constant is statistically sig- 
nificant and represents an annualized alpha of 2.21\%. Hence, existing currency strategies have problems explaining carry-trade returns, as is well established in the literature. Specifications II and VI include trend strategies consisting of interest rates, inflation, trade balance, economic activity, and the combo. We find that all trend strategies, except the one for the trade balance, have positive and strongly significant coefficients and render the alpha of carry trades insignificant. That trends in trade balances cannot explain the carry trade suggests that the model of adjustment of external imbalances presented by Gourinchas and Rey (2007) is distinct from any model aiming at explaining carry-trade returns. Moreover, our finding that changes in interest rates and yield spreads are significant determinants of carry-trade returns is different from that of Ang and Chen (2010), who document that monthly changes in interest rates are unrelated to carry-trade returns. While confirming their findings, we find that longer-term changes in rates emerge as significant determinants of carry-trade profits. When including the combo in specification VI, the carry-trade alpha declines to $0.10 \%$ per year. Specifications VII and VIII do the same for the time-series-carry strategy. Again, we find that the trend combo is a significant determinant of carry-trade returns, with the alpha becoming of less economic magnitude and statistically insignificant.

\subsection{Transaction costs and turnover}

It is reasonable to ask whether the documented profits of the trend strategies survive when taking transaction costs into account. The impact of trading costs on performance is a function of the costs themselves and the turnover of the strategy. We measure the average monthly turnover of the trend strategies and of the benchmark strategies by

$$
\frac{1}{T} \sum_{t=1}^{T} \sum_{c=1}^{C_{t}}\left|w_{c, t+1}-w_{c, t}\right|,
$$


where $w_{c, t}$ again denotes the weight of currency $c$ at time $t$. This measure can be interpreted as the average amount of total wealth traded each month.

We first study the turnover of the trend strategies based on the eight fundamental variables. The first plot in Figure 4 reports the turnover of each strategy and for short-, medium-, and long-term trends. It is evident that investing according to short-term rather than longterm trends is associated with higher turnover. This is intuitive, because short-term trends are less persistent. While short-term trends incur a turnover of more than 100\%, long-term trends incur an average turnover of $70 \%$. In addition, signals based on trade balance and measures of economic activity tend to have a higher turnover than do measures based on inflation or interest rates. The second plot in Figure 4 presents Sharpe ratios before transaction costs, showing that short-term trends tend to have lower Sharpe ratios than do mediumor long-term trends. Regarding which level of transaction costs to use, the working paper version of Menkhoff et al. (2012b) reports an average bid-ask spread for spot and forward rates of around ten basis points over the 1976-2010 period for developed markets. Mancini et al. (2013) report average bid-ask spreads of around five basis points for the most liquid currency pairs over the 2007-2009 period, albeit with occasional spikes during the financial crisis. An investor incurs a cost of half the spread when buying or selling a currency. Assuming a bid-ask spread of ten basis points, the difference in performance between short-term and long-term trends becomes even more obvious. The low gross Sharpe ratios together with high turnover imply that the net Sharpe ratios are even lower for short-term than for medium- or long-term trends, in some cases even approaching zero.

Next we report the turnover of the trend combo and benchmark strategies in Table 10. The trend combo has an average monthly turnover of $85 \%$, which is similar to that of the cross-sectional benchmark strategies but higher than that of the time-series strategies. The dollar-carry and long-only strategies have the lowest turnovers. Note that the turnover of a strategy is a function of the leverage of the strategy, the change in the actual investment 
signal, and the change in the volatility of the strategy, because portfolio weights are scaled by past volatility. This explains why the long-only strategy has a positive turnover. Despite being long a basket of all foreign currencies in each period, the realized volatility of the strategy changes, causing portfolio weights to change.

The fact that strategies with cross-sectional weighting have higher turnover than do strategies with time-series weighting reflects the fact that a currency changes its crosssectional rank more often than the sign of a currency's signal switches. Table 10 reports Sharpe ratios net of transaction costs, assuming three different transaction costs based on bid-ask spreads of five, ten, and 15 basis points. Assuming a spread of 15 basis points, the trend combo generates a Sharpe ratio of 0.96, which is higher than those of the benchmark strategies. Hence, even after taking costs into account, investing in currencies based on past trends in fundamentals seems profitable.

\section{Investors' expectations of fundamentals}

A recent and growing literature has found that investors' expectations of future returns on a range of financial assets tend to be extrapolative. That is, investors expect high (low) future returns if recent realized returns are positive (negative). However, there is less empirical evidence as to whether investors' expectations of fundamentals are also extrapolative. We study whether this is the case using survey expectations from the World Economic Survey. We run panel regressions using survey results for a particular economic variable as the dependent variable and recent short-term trends in the forecasted economic variable as the independent variable. More specifically, we use the past three-month change (or log change) to measure past trends, because the literature on the extrapolation of return expectations suggests that investors put the most weight on recent trends. ${ }^{13}$ As described earlier, the

\footnotetext{
${ }^{13}$ The online appendix reports evidence of extrapolation even for horizons longer than three months. In unreported results, we also find evidence of extrapolation across a range of variables, using expectations from
} 
World Economic Survey is sent to investors during the first month of each quarter, and its results are then released in the second month. We align the regressions such that surveys conducted during the current quarter are mapped to past trends as of the end of the previous quarter. For example, trends in fundamental variables ending 31 December 1990 are used to explain surveys conducted in January 1991 and subsequently released in February 1991. This guarantees that past trends are part of the investors' information set when they complete the survey.

Table 11 reports results for seven surveys representing short rates, yield spreads, long rates, inflation, trade balance, economic activity, and local currency appreciation (USD depreciation). All regressions return positive and significant coefficients. This suggests that investors' beliefs, across variables and countries, are uniformly extrapolative. The finding that investors' beliefs about future currency appreciation are extrapolative was recently documented by Koijen et al. (2015). ${ }^{14}$ In the online appendix, we report that controlling for lagged surveys in the regressions yields similar results.

We also study how investor beliefs relate to the portfolio weights, which measure the relative ranks of economic trends across countries. Table 12 reports relevant results and shows that surveys tend to load negatively on the weights, with the exception of survey results about trade balances. This suggests that investors tend to expect a decrease (increase) in a variable when past trends in that variable rank high (low) compared with those in other countries. Controlling for lagged surveys strengthens the results, as reported in the online appendix. The negative coefficient in the last column suggests that the model-implied expected returns and investors' views of currency returns are inversely related. That is, when the model indicates high expected returns on a currency, investors believe in low returns in the form of future depreciation.

the Survey of Professional Forecasters.

${ }^{14}$ While we use lagged currency excess returns in the table, the results also hold for currency appreciation. 
That investors' beliefs seem to have the "wrong" sign suggests that investing according to their beliefs about future currency appreciation would yield negative performance. Indeed, we find this to be true, as reported in Table 13. This result has recently been documented by Koijen et al. (2015). Motivated by the potential bias in investors' beliefs, we also consider strategies that invest according to investors' views of future fundamentals. We go long (short) currencies in countries whose investors believe in an increase (decrease) in the respective fundamental variable. We consider strategies that employ cross-sectional ranking and also strategies that use time-series weighting. In the latter case, a currency's signal is determined by investors' expectations in the foreign country minus US investors' expectations of the same variable. That is, when foreign investors are more optimistic (pessimistic) about a fundamental variable, we go long (short) the foreign currency versus the USD. The table reports negative Sharpe ratios across the board; the time-series strategies in particular yield negative performance. It seems that investing according to investors' beliefs about inflation and economic activity yields the worst performance. Hence, investing in countries for which investors expect stronger economic growth, higher inflation, and tighter monetary policy in the form of higher short rates seems to be a losing proposition. That the negative performance is greatest for time-series strategies may reflect the uniform evidence of extrapolative beliefs.

\section{Conclusion}

We document that past trends in fundamentals positively predict currency returns. A strategy that goes long (short) currencies whose countries have experienced strong (weak) economic momentum returns a Sharpe ratio of around one and yields significant alpha when controlling for existing currency strategies. Returns on the economic momentum strategy subsume the alpha of carry trades, which suggests that sorting on carry is captured by sort- 
ing on past trends in fundamentals. That more than half of the economic momentum returns are left unexplained by standard strategies means that investing according to economic momentum represents an additional source of returns. We discuss possible explanations for the returns, but their exact source remains an open question. In addition, we document that investors' expectations of future fundamentals are extrapolative across a broad range of economic variables and countries. Currency strategies that invest in countries for which investors expect tighter monetary policy, stronger growth, and higher inflation all exhibit negative Sharpe ratios. It would be interesting to investigate the theoretical link between exchange rates and extrapolative beliefs about fundamentals. 


\section{References}

Andrews, Donald W.K., 1991, Heteroskedasticity and autocorrelation consistent covariance matrix estimation, Econometrica 59, 817-858.

Ang, Andrew, and Joseph S. Chen, 2010, Yield curve predictors of foreign exchange returns, Working Paper.

Asness, Clifford S., Tobias J. Moskowitz, and Lasse Heje Pedersen, 2013, Value and momentum everywhere, Journal of Finance 68, 929-985.

Baltas, Nick, and Robert Kosowski, 2015, Demystifying time-series momentum strategies: Volatility estimators, trading rules, and pairwise correlations, Working Paper.

Barberis, Nicholas, Robin Greenwood, Lawrence Jin, and Andrei Shleifer, 2015, X-CAPM: An extrapolative capital asset pricing model, Journal of Financial Economics 115, 1-24.

Barroso, Pedro, and Pedro Santa-Clara, 2013, Beyond the carry trade: Optimal currency portfolios, forthcoming in Journal of Financial and Quantitative Analysis.

Brunnermeier, Markus K., Stefan Nagel, and Lasse H. Pedersen, 2009, Carry trades and currency crashes, in Daron Acemoglu, Kenneth Rogoff, and Michael Woodford, eds.: NBER Macroeconomics Annual, Volume 23 (MIT Press, Cambridge ).

Burnside, Craig, Martin Eichenbaum, Isaac Kleshchelski, and Sergio Rebelo, 2011, Do peso problems explain the returns to the carry trade?, Review of Financial Studies 24, 853-891.

Chernov, Mikhail, Jeremy Graveline, and Irina Zviadadze, 2014, Crash risk in currency returns, Working Paper.

Choi, James J., and Thomas M. Mertens, 2013, Extrapolative expectations and the equity premium, Working Paper.

Daniel, Kent, Robert J. Hodrick, and Zhongjin Lu, 2014, The carry trade: Risks and drawdowns, Working Paper.

Della Corte, Pasquale, Steven J. Riddiough, and Lucio Sarno, 2014, Currency premia and global imbalances, Working Paper.

Della Corte, Pasquale, Lucio Sarno, and Giulia Sestieri, 2012, The predictive information content of external imbalances for exchange rate returns: How much is it worth?, Review of Economics and Statistics 94, 100-115.

Engel, Charles, 2014, Exchange rates and interest parity, in Elhanan Helpman, Kenneth Rogoff, and Gita Gopinath, eds.: Handbook of International Economics, Volume 4 (Elsevier, Amsterdam ). 
Engel, Charles, Nelson C. Mark, and Kenneth D. West, 2007, Exchange rate models are not as bad as you think, in Daron Acemoglu, Kenneth Rogoff, and Michael Woodford, eds.: NBER Macroeconomics Annual, Volume 22 (MIT Press, Cambridge ).

Engel, Charles, and Kenneth D. West, 2005, Exchange rates and fundamentals, Journal of Political Economy 113, 485-517.

Farhi, Emmanuel, Samuel P. Fraiberger, Xavier Gabaix, Romain Ranciere, and Adrien Verdelhan, 2014, Crash risk in currency markets, Working Paper.

Fleming, Jeff, Chris Kirby, and Barbara Ostdiek, 2001, The economic value of volatility timing, Journal of Finance 56, 329-352.

Fuster, Andreas, Benjamin Hebert, and David Laibson, 2011, Natural expectations, macroeconomic dynamics, and asset pricing, NBER Working Paper.

Fuster, Andreas, David Laibson, and Brock Mendel, 2010, Natural expectations and macroeconomic fluctuations, Journal of Economic Perspectives 24, 67-84.

Gourinchas, Pierre-Olivier, and Hélène Rey, 2007, International financial adjustment, Journal of Political Economy 115, 665-703.

Greenwood, Robin, and Andrei Shleifer, 2014, Expectations of returns and expected returns, Review of Financial Studies 27, 714-746.

Hassan, Tarek K., and Rui C. Mano, 2014, Forward and spot exchange rates in a multicurrency world, Working Paper.

Hirshleifer, David, Jun Li, and Jianfeng Yu, 2015, Asset pricing in production economies with extrapolative expectations, Working Paper.

Jordà, Òscar, and Alan M. Taylor, 2012, The carry trade and fundamentals: Nothing to fear but FEER itself, Journal of International Economics 88, 74-90.

Jurek, Jakub W., 2014, Crash-neutral currency carry trades, Journal of Financial Economics $113,325-347$.

Kirby, Chris, and Barbara Ostdiek, 2012, It's all in the timing: Simple active portfolio strategies that outperform naïve diversification, Journal of Financial and Quantitative Analysis 47, 437-467.

Koijen, Ralph S.J., Tobias J. Moskowitz, Lasse Heje Pedersen, and Evert B. Vrugt, 2013, Carry, Working Paper.

Koijen, Ralph S.J., Maik Schmeling, and Evert B. Vrugt, 2015, Survey expectations of returns and asset pricing puzzles, Working Paper. 
Kudymowa, Evgenia, Johanna Plenk, and Klaus Wohlrabe, 2013, Ifo world economic survey and the business cycle in selected countries, CESifo Forum 14, 51-57.

Lettau, Martin, Matteo Maggiori, and Michael Weber, 2014, Conditional risk premia in currency markets and other asset classes, Journal of Financial Economics 114, 197-225.

Lustig, Hanno, Nikolai Roussanov, and Adrien Verdelhan, 2011, Common risk factors in currency markets, Review of Financial Studies 24, 3731-3777.

Lustig, Hanno, Nikolai Roussanov, and Adrien Verdelhan, 2014, Countercyclical currency risk premia, Journal of Financial Economics 111, 527-553.

Lustig, Hanno, and Adrien Verdelhan, 2007, The cross-section of foreign currency risk premia and US consumption growth risk, American Economic Review 97, 89-117.

Malmendier, Ulrike, and Stefan Nagel, 2014, Learning from inflation experiences, Quarterly Journal of Economics, forthcoming.

Mancini, Loriano, Angelo Ranaldo, and Jan Wrampelmeyer, 2013, Liquidity in the foreign exchange market: Measurement, commonality, and risk premiums, Journal of Finance 68, $1805-1841$.

Meese, Richard A., and Kenneth Rogoff, 1983, Empirical exchange rate models of the seventies: Do they fit out of sample?, Journal of International Economics 1983, 3-24.

Menkhoff, Lukas, Lucio Sarno, Maik Schmeling, and Andreas Schrimpf, 2012a, Carry trades and global foreign exchange volatility, Journal of Finance 67, 681-718.

Menkhoff, Lukas, Lucio Sarno, Maik Schmeling, and Andreas Schrimpf, 2012b, Currency momentum strategies, Journal of Financial Economics 106, 660-684.

Menkhoff, Lukas, Lucio Sarno, Maik Schmeling, and Andreas Schrimpf, 2015, Currency Value, Working Paper.

Moskowitz, Tobias J., Yao Hua Ooi, and Lasse Heje Pedersen, 2012, Time series momentum, Journal of Financial Economics 104, 228-250.

Newey, Whitney K., and Kenneth D. West, 1987, A simple, positive semi-definite, heteroskedasticity and autocorrelation consistent covariance matrix, Econometrica 55, 703708.

Newey, Whitney K., and Kenneth D. West, 1994, Automatic lag selection in covariance matrix estimation, Review of Economic Studies 61, 631-653.

Rapach, David, and Guofo Zhou, 2013, Forecasting stock returns, in Graham Elliott, and Allan Timmermann, eds.: Handbook of Economic Forecasting, Volume 2 A (Elsevier, Amsterdam ). 
Sarno, Lucio, and Maik Schmeling, 2014, Which fundamentals drive exchange rates? A cross-sectional perspective, Journal of Money, Credit and Banking 46, 267-292.

Stangl, Anna, 2007, Ifo world economic survey micro data, Journal of Applied Social Science Annual 127, 487-496.

Taylor, John B., 1993, Discretion versus policy rules in practice, Carnegie-Rochester Conference Series on Public Policy 39, 195-214.

Wright, Jonathan H., 2008, Bayesian model averaging and exchange rate forecasts, Journal of Econometrics 146, 329-341. 


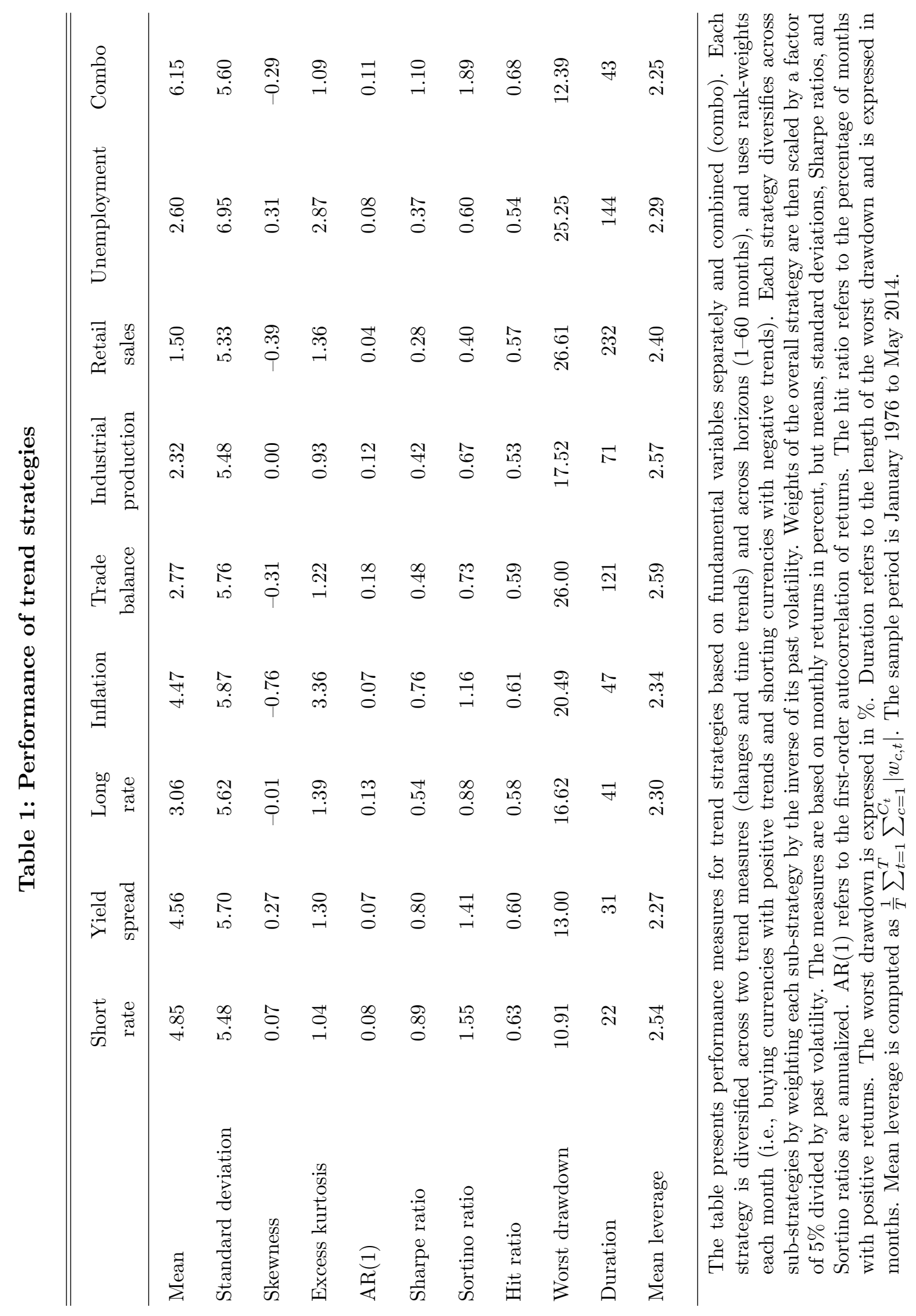




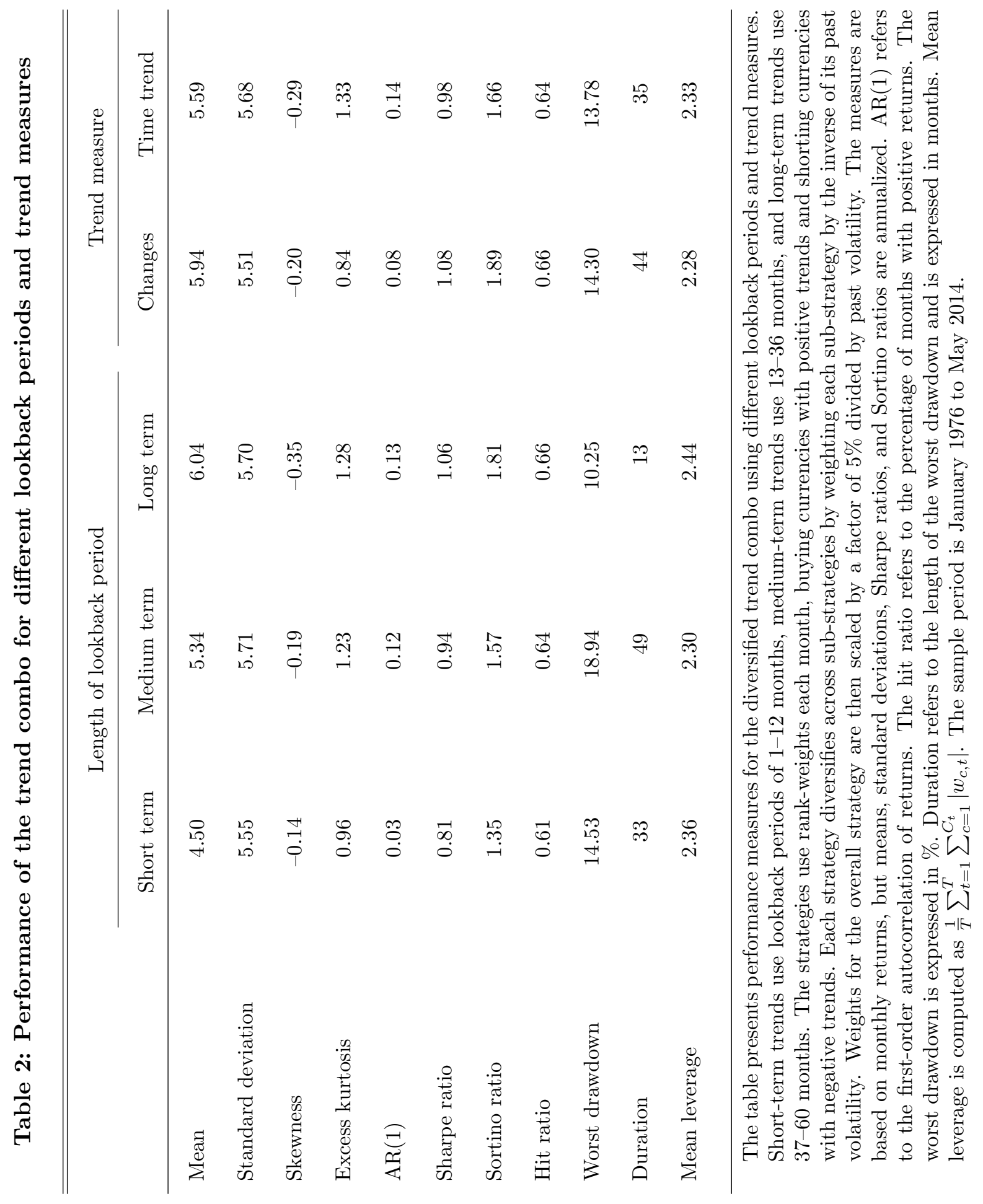




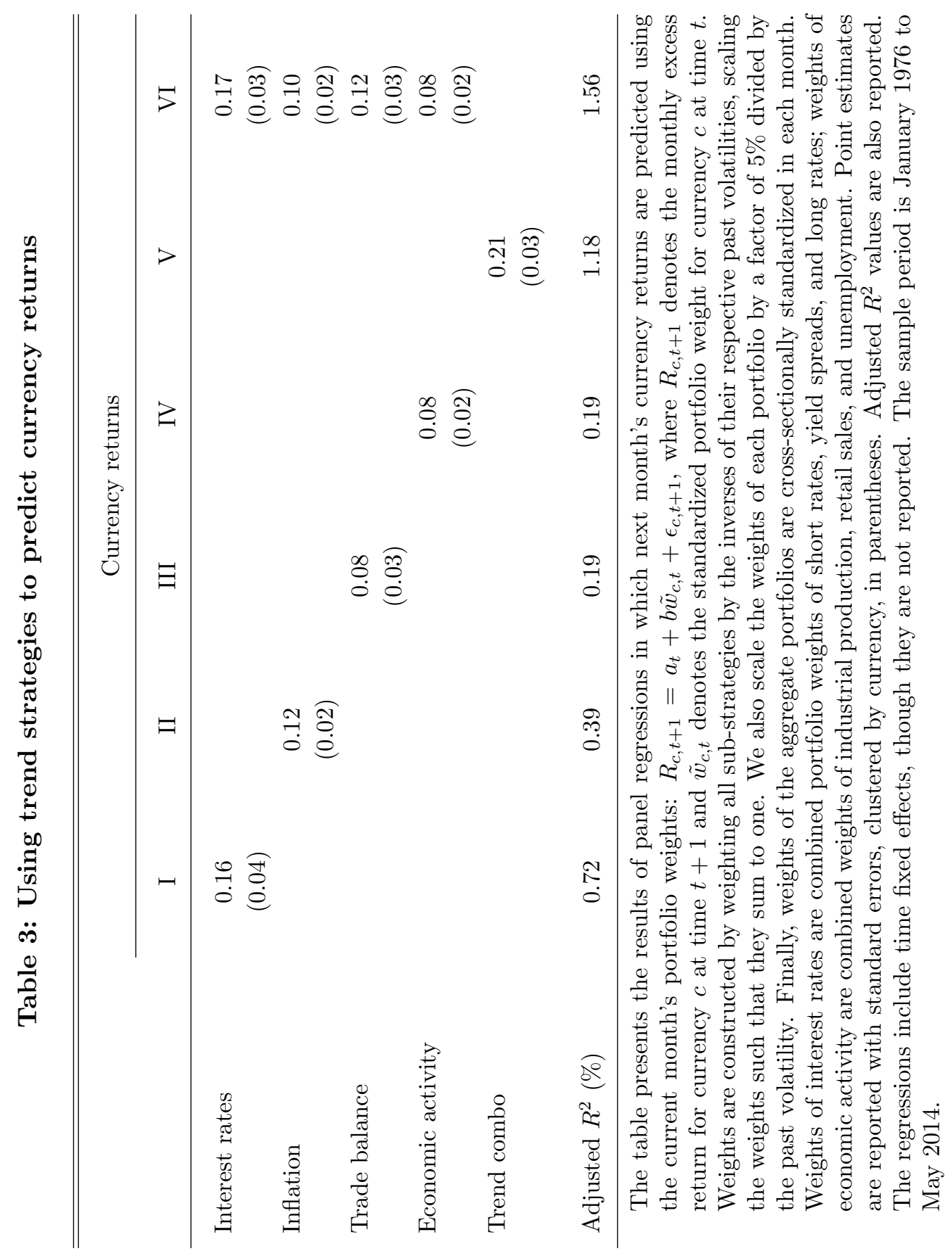




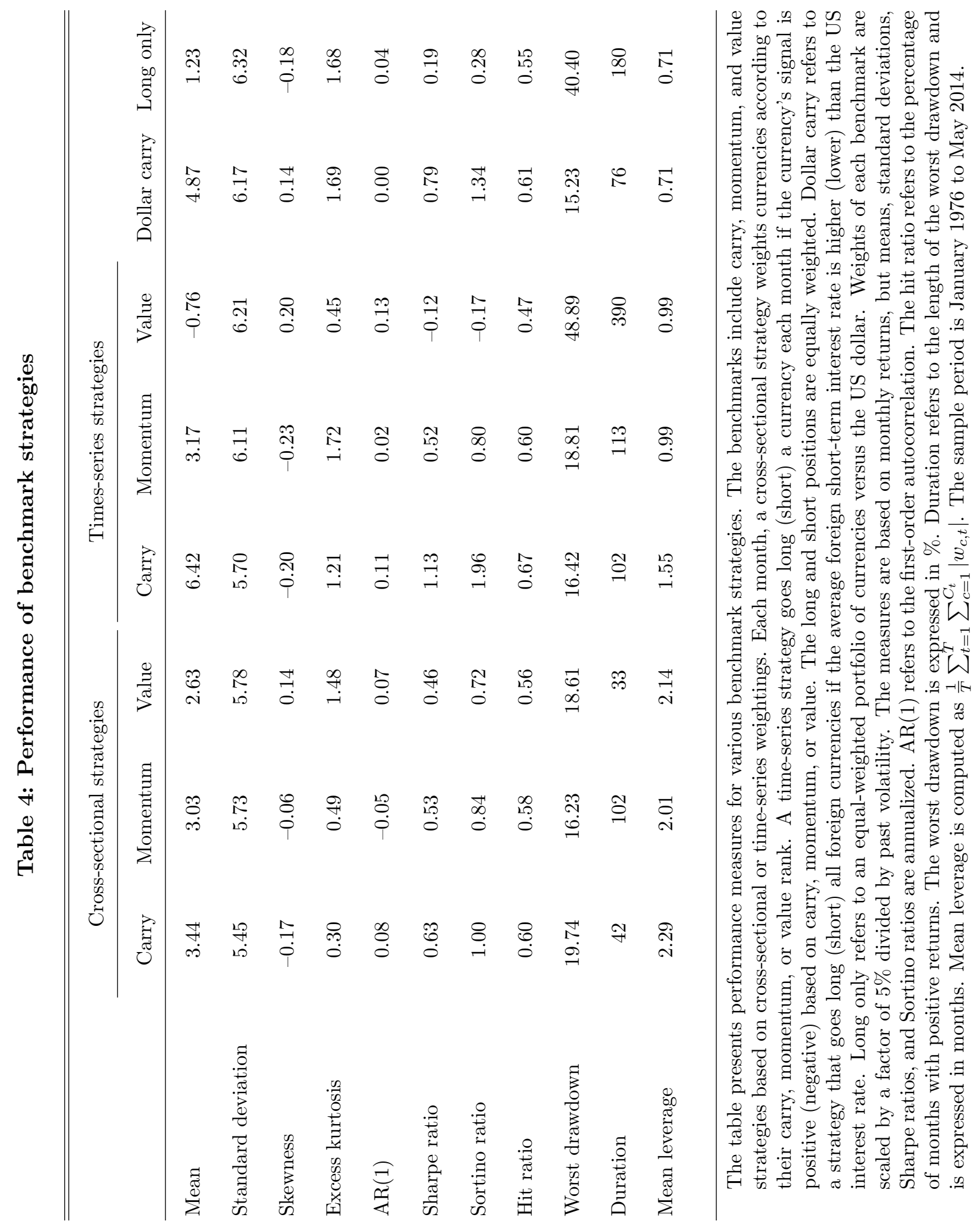


Table 5: Returns of the trend combo on benchmark strategies

\begin{tabular}{|c|c|c|c|}
\hline & \multicolumn{3}{|c|}{ Returns on trend combo } \\
\hline & $\mathrm{I}$ & II & III \\
\hline Constant & $\begin{array}{c}3.22 \\
(0.84)\end{array}$ & $\begin{array}{c}3.37 \\
(0.90)\end{array}$ & $\begin{array}{c}0.36 \\
(0.11)\end{array}$ \\
\hline Dollar carry & $\begin{array}{c}0.07 \\
(0.06)\end{array}$ & $\begin{array}{l}-0.19 \\
(0.08)\end{array}$ & $\begin{array}{c}0.24 \\
(0.11)\end{array}$ \\
\hline Long only & $\begin{array}{c}-0.02 \\
(0.05)\end{array}$ & $\begin{array}{c}-0.20 \\
(0.07)\end{array}$ & $\begin{array}{l}-0.03 \\
(0.11)\end{array}$ \\
\hline CS Carry & $\begin{array}{c}0.51 \\
(0.06)\end{array}$ & & \\
\hline CS Momentum & $\begin{array}{c}0.18 \\
(0.06)\end{array}$ & & \\
\hline CS Value & $\begin{array}{c}0.14 \\
(0.07)\end{array}$ & & \\
\hline TS Carry & & $\begin{array}{c}0.61 \\
(0.09)\end{array}$ & \\
\hline TS Momentum & & $\begin{array}{c}0.02 \\
(0.06)\end{array}$ & \\
\hline TS Value & & $\begin{array}{c}0.03 \\
(0.08)\end{array}$ & \\
\hline$\Delta \mathrm{FXVOL}$ & & & $\begin{array}{r}-10.22 \\
(9.33)\end{array}$ \\
\hline$\triangle \mathrm{TED}$ & & & $\begin{array}{l}-0.70 \\
(0.32)\end{array}$ \\
\hline$\Delta$ VIX & & & $\begin{array}{c}-0.04 \\
(0.03)\end{array}$ \\
\hline Appraisal ratio & 0.72 & 0.71 & \\
\hline Adjusted $R^{2}(\%)$ & 34.65 & 27.15 & 9.02 \\
\hline
\end{tabular}

The table presents a contemporaneous regression of the monthly returns of the trend combo on benchmark strategies and changes in measures of volatility and funding conditions. Appraisal ratio refers to the constant of the regression divided by the standard deviation of the residuals. Constants in specifications I and II are annualized alphas. Specification III uses changes in foreign exchange volatility (FXVOL), the TED spread, and the VIX volatility index, which are non-traded factors, so the constant cannot be interpreted as alpha (no appraisal ratio is then reported). Point estimates are reported with Newey and West (1987) standard errors, accounting for conditional heteroscedasticity and serial correlation up to twelve lags, in parentheses. Adjusted $R^{2}$ values are also reported. The sample period is January 1976 to May 2014, except for specification III which starts in January 1990 due to data availability for the VIX volatility index. 


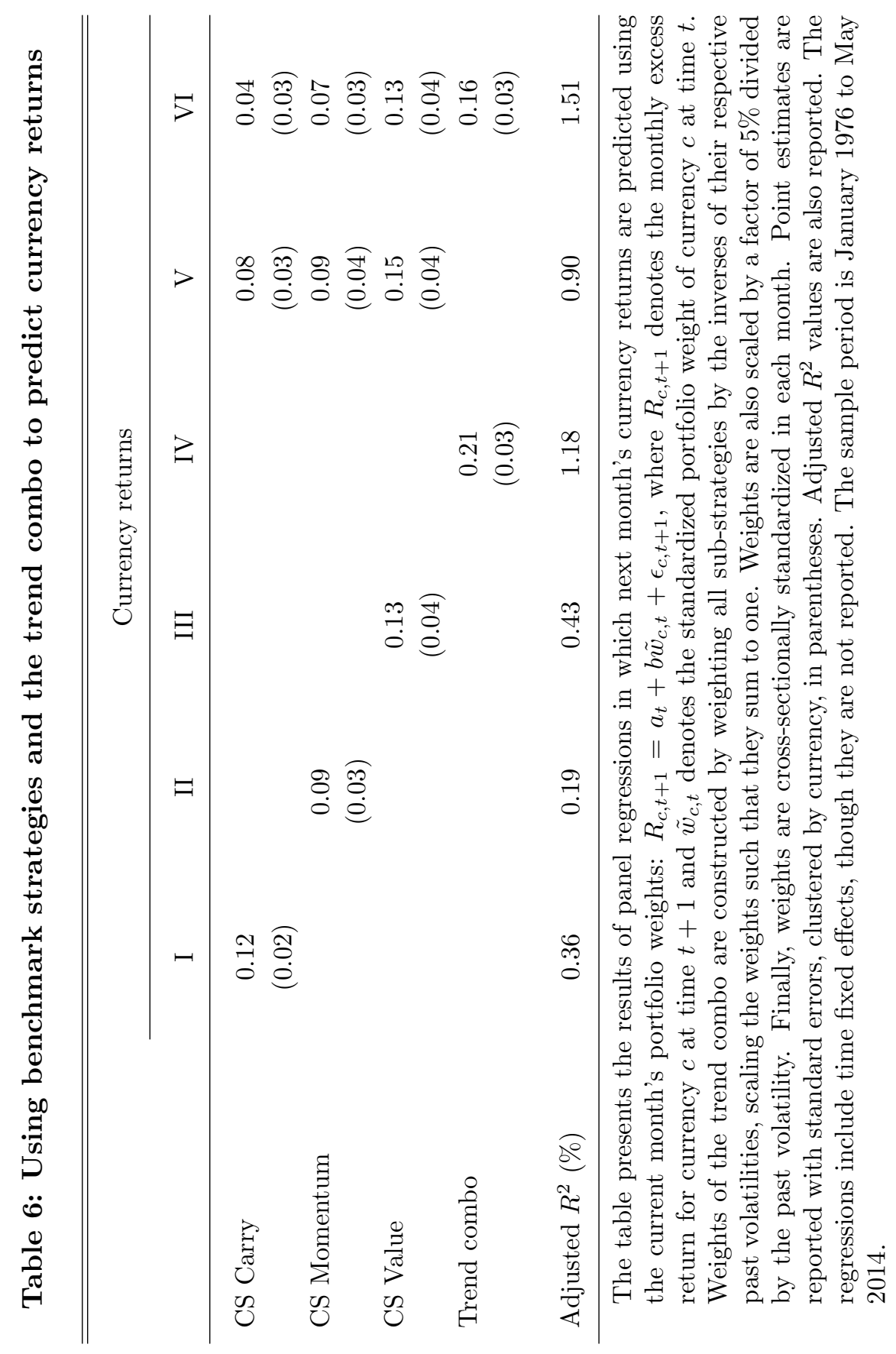


Table 7: Predicting currency returns over various forecasting horizons

\begin{tabular}{lcccc}
\hline \hline & \multicolumn{4}{c}{ Cumulative currency returns } \\
\cline { 2 - 5 } & 1 month & 3 months & 6 months & 12 months \\
\hline \multirow{2}{*}{ CS Carry } & 0.04 & 0.02 & 0.01 & 0.01 \\
CS Momentum & $(0.03)$ & $(0.03)$ & $(0.03)$ & $(0.04)$ \\
CS Value & 0.07 & 0.05 & 0.02 & -0.01 \\
Trend combo & $(0.03)$ & $(0.03)$ & $(0.02)$ & $(0.02)$ \\
& 0.13 & 0.14 & 0.14 & 0.12 \\
Adjusted $R^{2}(\%)$ & $(0.04)$ & $(0.03)$ & $(0.03)$ & $(0.03)$ \\
& 0.16 & 0.14 & 0.14 & 0.14 \\
& $(0.03)$ & $(0.03)$ & $(0.03)$ & $(0.03)$ \\
The table & 1.51 & 3.57 & 6.29 & 11.60 \\
\hline
\end{tabular}

The table presents the results of panel regressions in which future cumulative currency returns over one-, three, six-, and 12-month horizons are predicted along with current portfolio weights of three benchmark strategies (i.e., carry, momentum, and cross-sectional value) and the trend combo. The cumulative returns are scaled on a monthly basis to facilitate the interpretation of the coefficients. Point estimates are reported with standard errors, clustered by currency, in parentheses. Adjusted $R^{2}$ values are also reported. The regressions include time fixed effects, though they are not reported. The sample period is January 1976 to May 2014. 
Table 8: Predicting dollar depreciation over various forecasting horizons

\begin{tabular}{lcccc}
\hline \hline & \multicolumn{4}{c}{ Cumulative dollar depreciations } \\
\cline { 2 - 5 } & 1 month & 3 months & 6 months & 12 months \\
\hline \multirow{2}{*}{ CS Carry } & -0.09 & -0.10 & -0.11 & -0.11 \\
& $(0.04)$ & $(0.04)$ & $(0.04)$ & $(0.04)$ \\
CS Momentum & 0.03 & 0.01 & -0.02 & -0.04 \\
CS Value & $(0.03)$ & $(0.04)$ & $(0.03)$ & $(0.02)$ \\
Trend combo & 0.12 & 0.13 & 0.13 & 0.12 \\
& $(0.04)$ & $(0.03)$ & $(0.03)$ & $(0.03)$ \\
Adjusted $R^{2}(\%)$ & 0.07 & 0.06 & 0.06 & 0.07 \\
\hline
\end{tabular}

The table presents the results of panel regressions in which future cumulative dollar depreciations over one-, three, six-, and 12-month horizons are predicted along with current portfolio weights of three benchmark strategies (i.e., carry, momentum, and cross-sectional value) and the trend combo. The cumulative returns are scaled on a monthly basis to facilitate the interpretation of the coefficients. Point estimates are reported with standard errors, clustered by currency, in parentheses. Adjusted $R^{2}$ values are also reported. The regressions include time fixed effects, though they are not reported. The sample period is January 1976 to May 2014. 


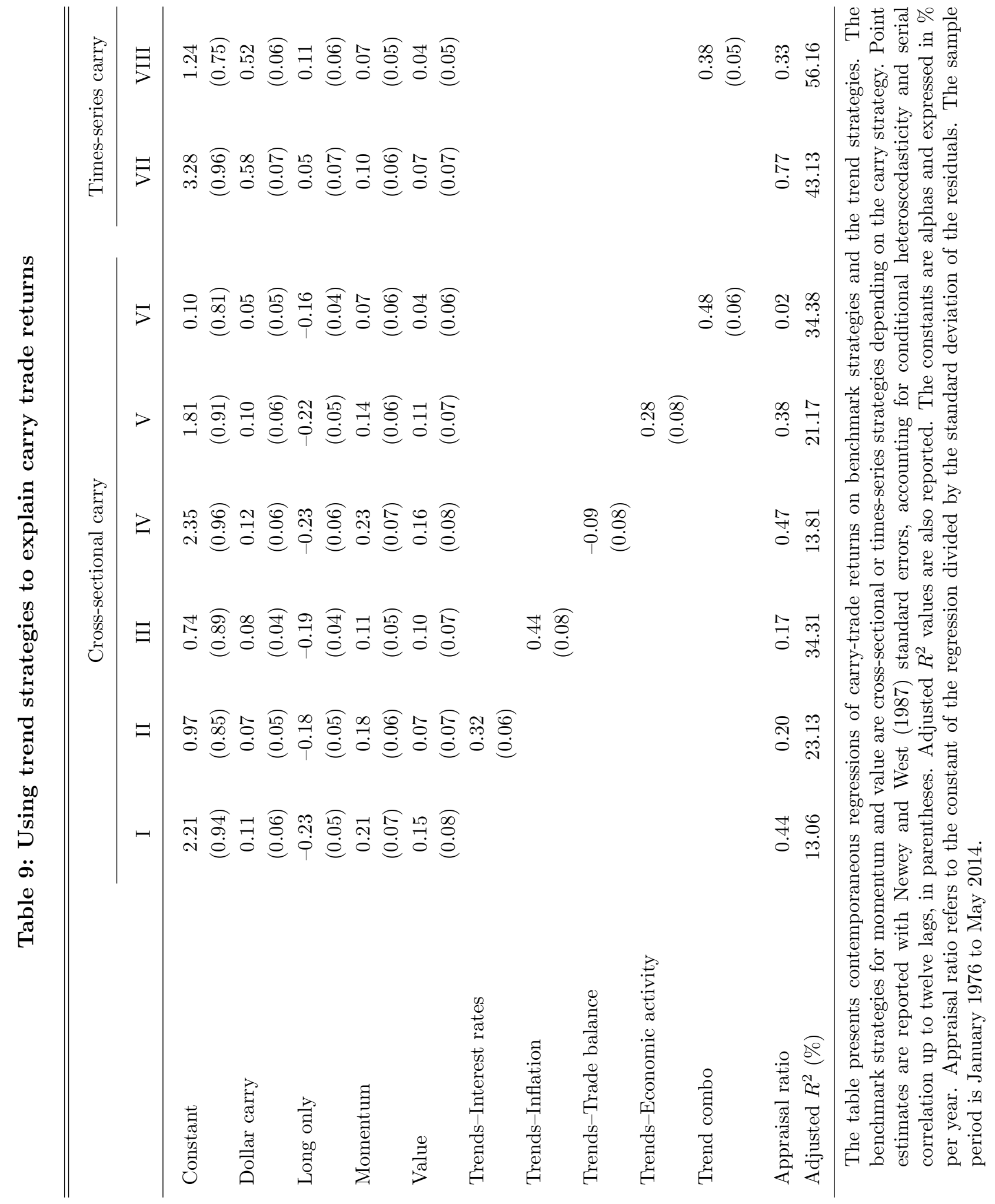




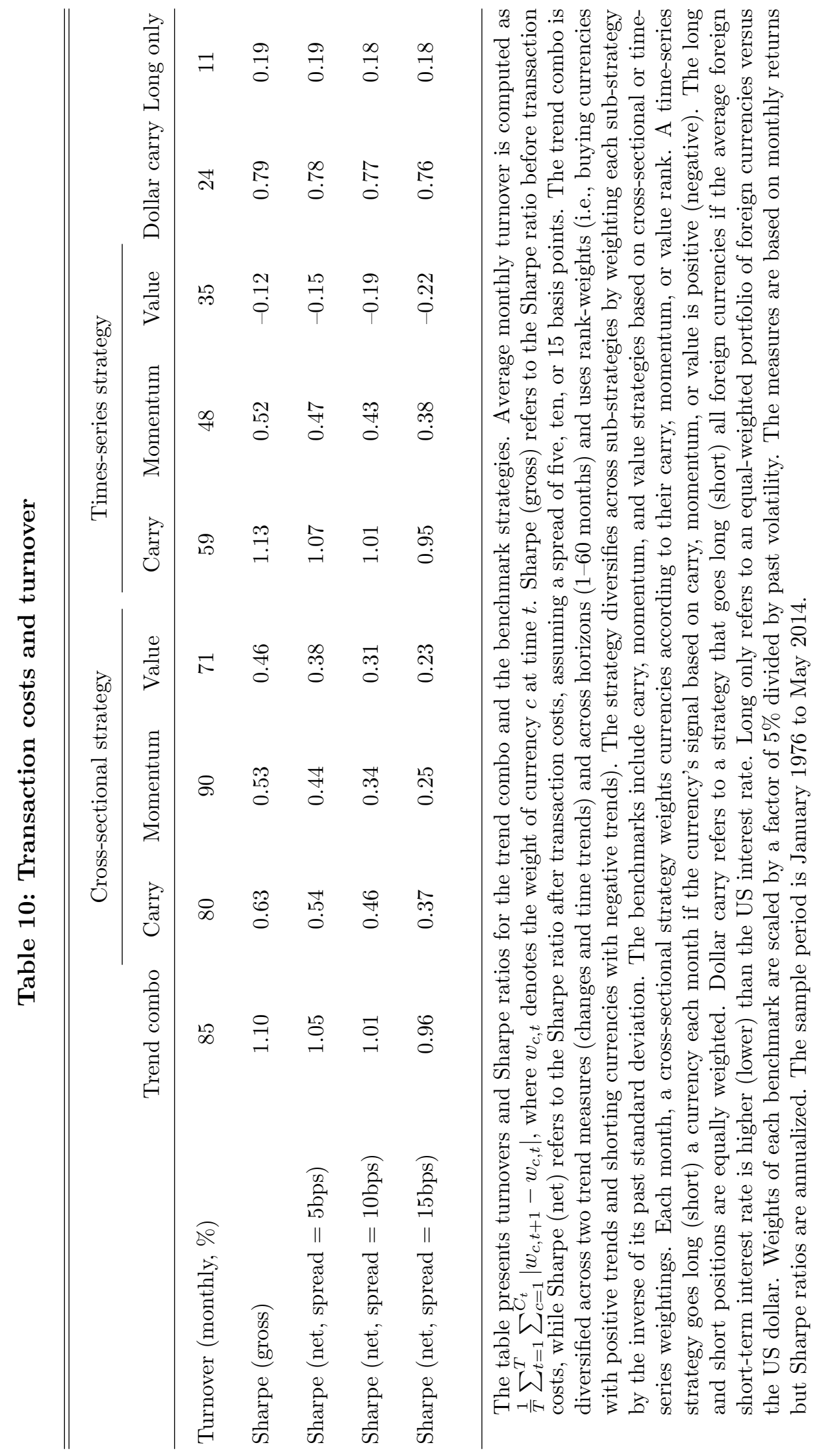




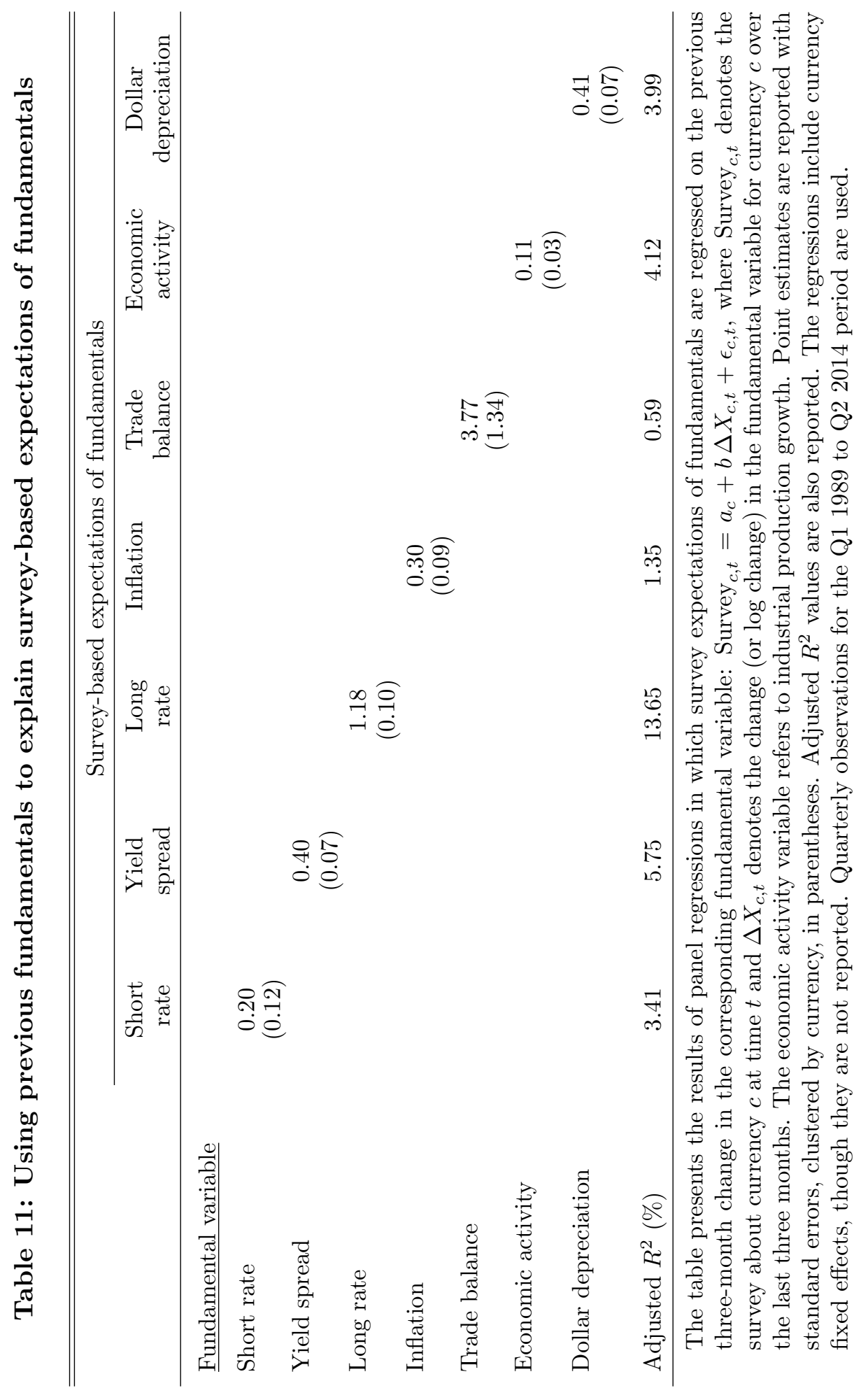




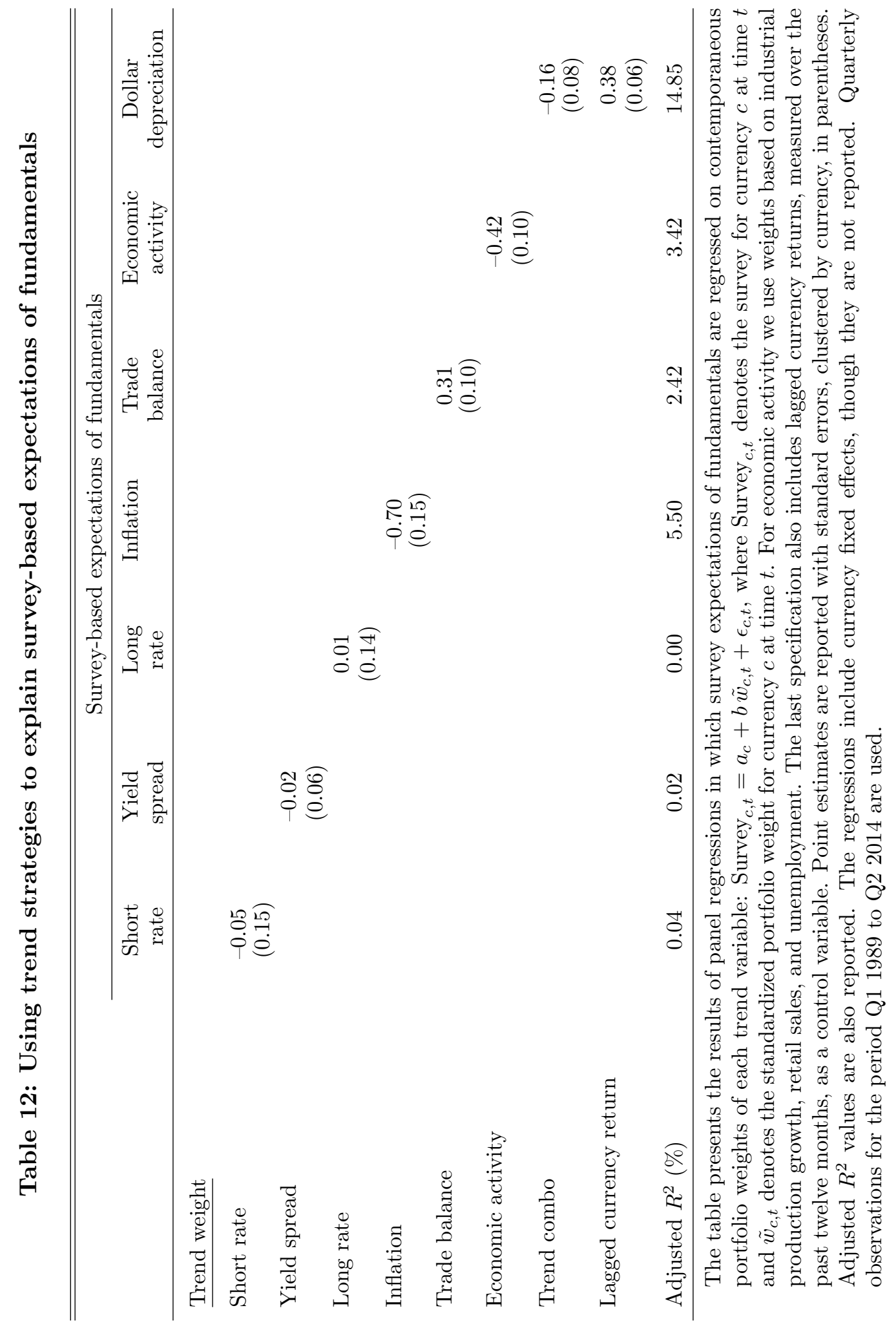




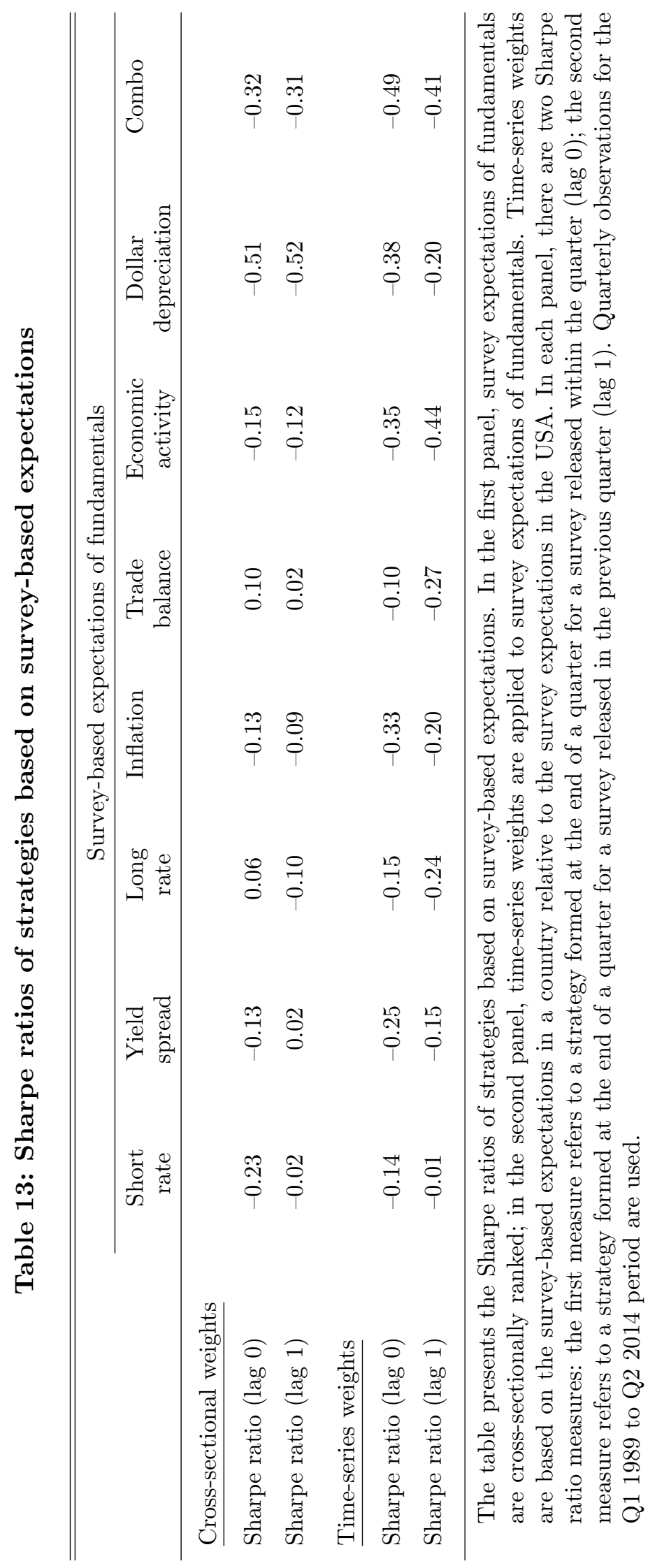


Figure 1: Sharpe ratios of trend strategies - changes
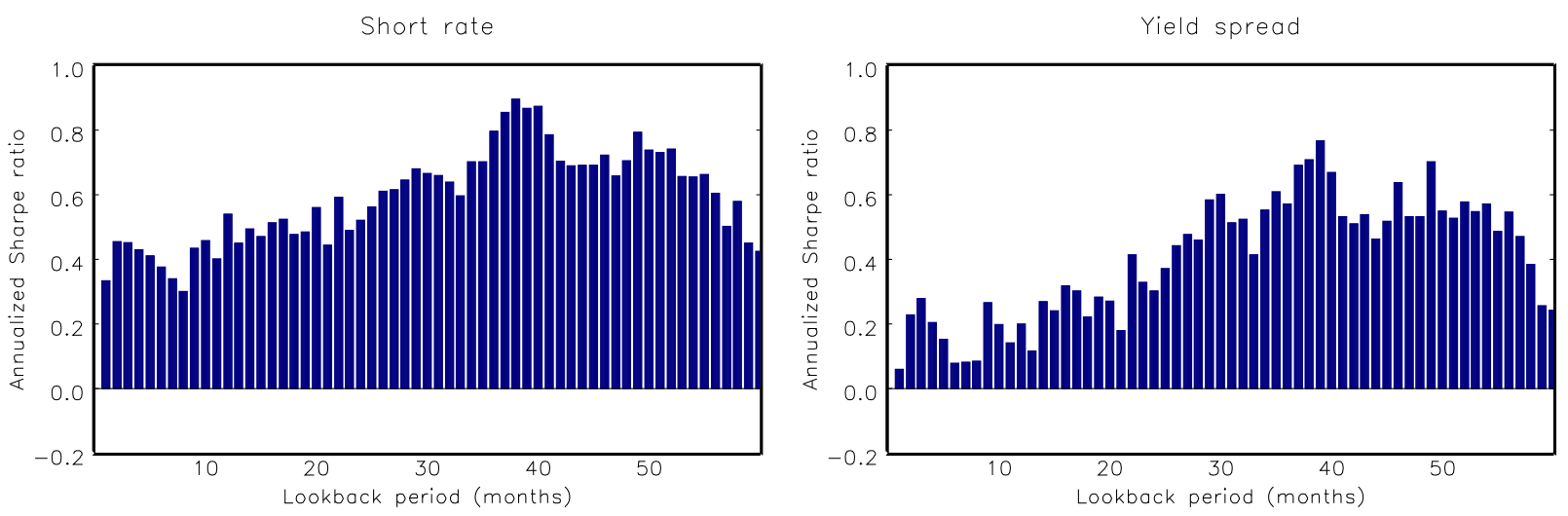

Long rate
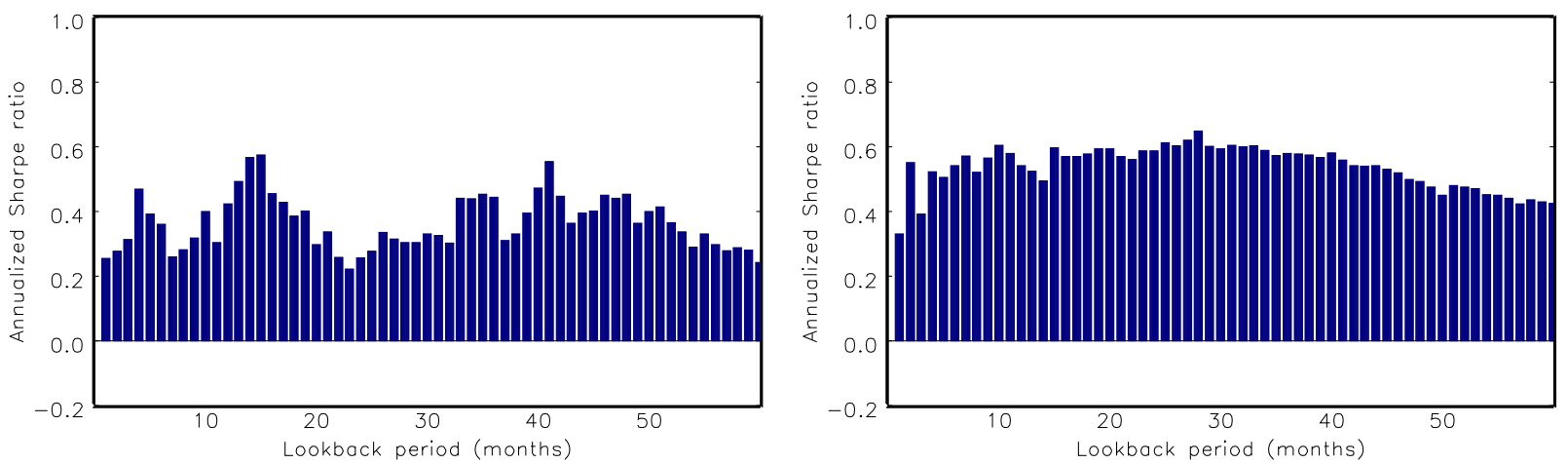

Trade balance

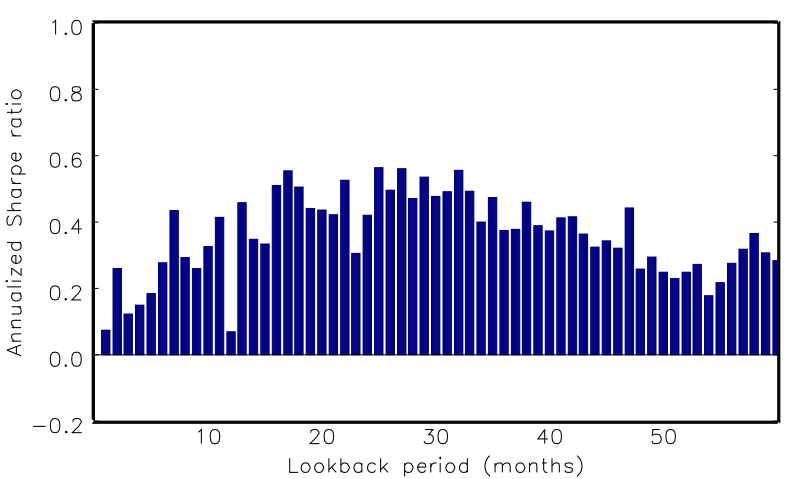

Industrial production

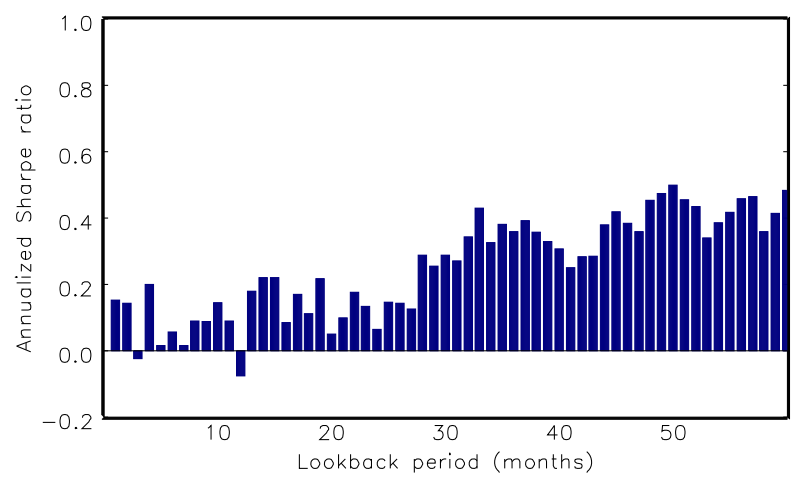

Retail sales
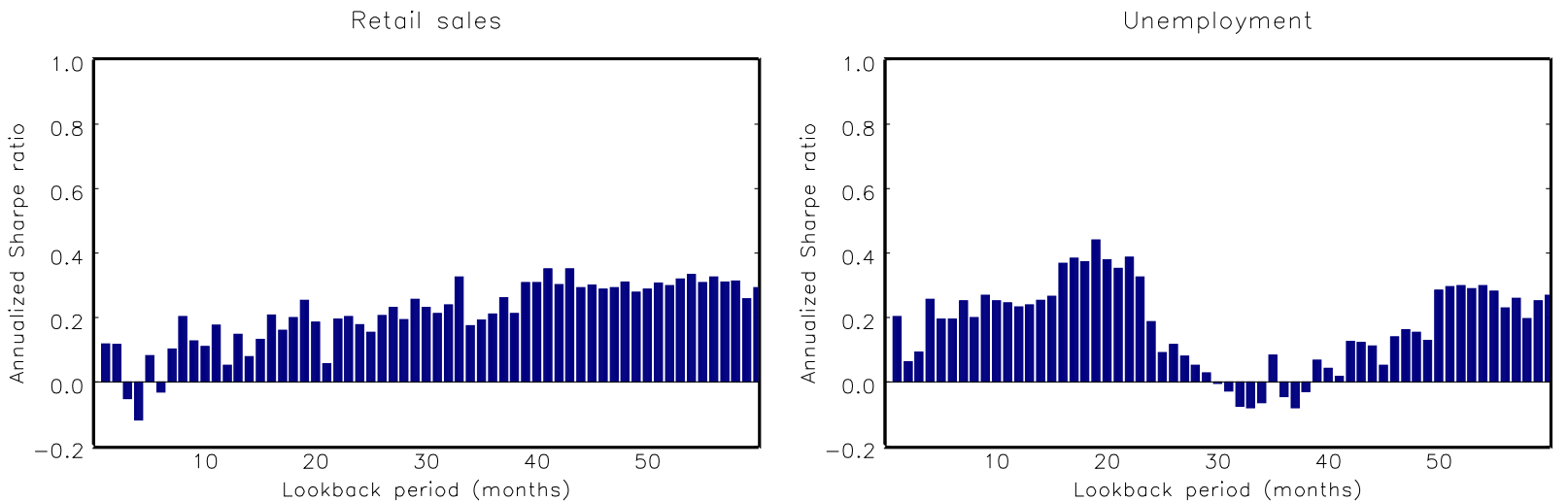

The figure shows annualized Sharpe ratios for fundamental variables versus lookback periods. Each month, each strategy ranks each country according to the strength of past trends in each variable using changes (or log changes) over a range of lookback periods. Each strategy then uses rank-based portfolio weights and goes long currencies with positive trends and short currencies with negative trends. The inverse of unemployment and flattening of yield spreads are used so that increases in the variables indicate improving economic conditions. The sample period is January 1976 to May 2014. 
Figure 2: Sharpe ratios of trend strategies - time trend
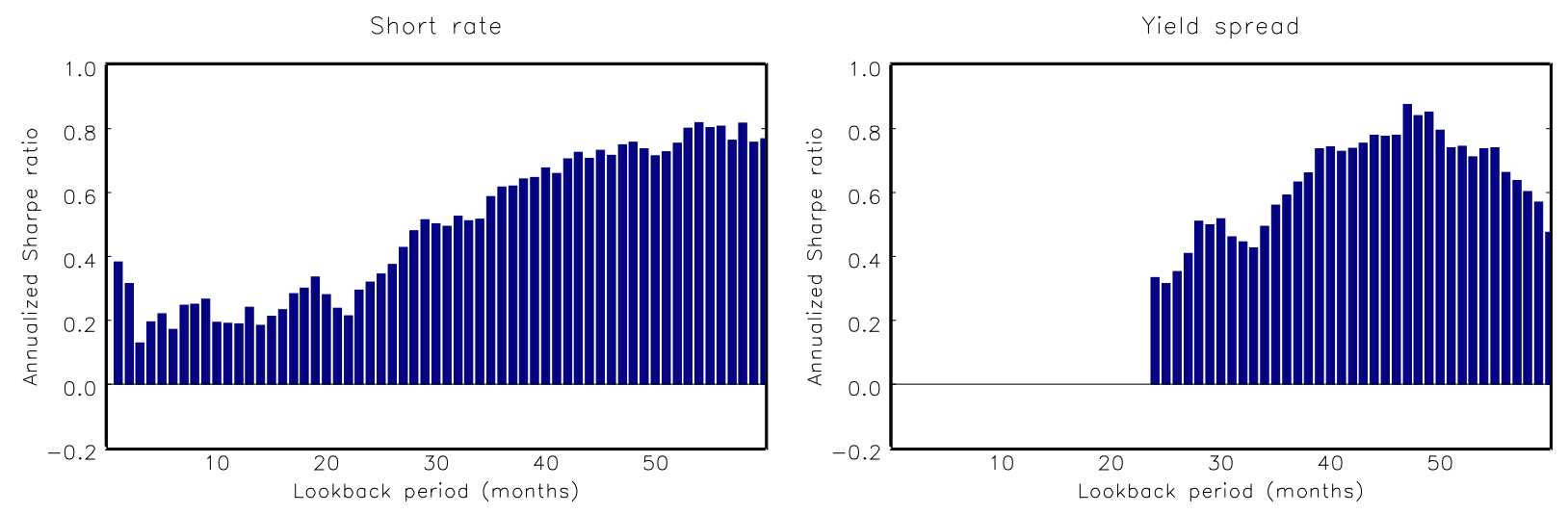

Long rate
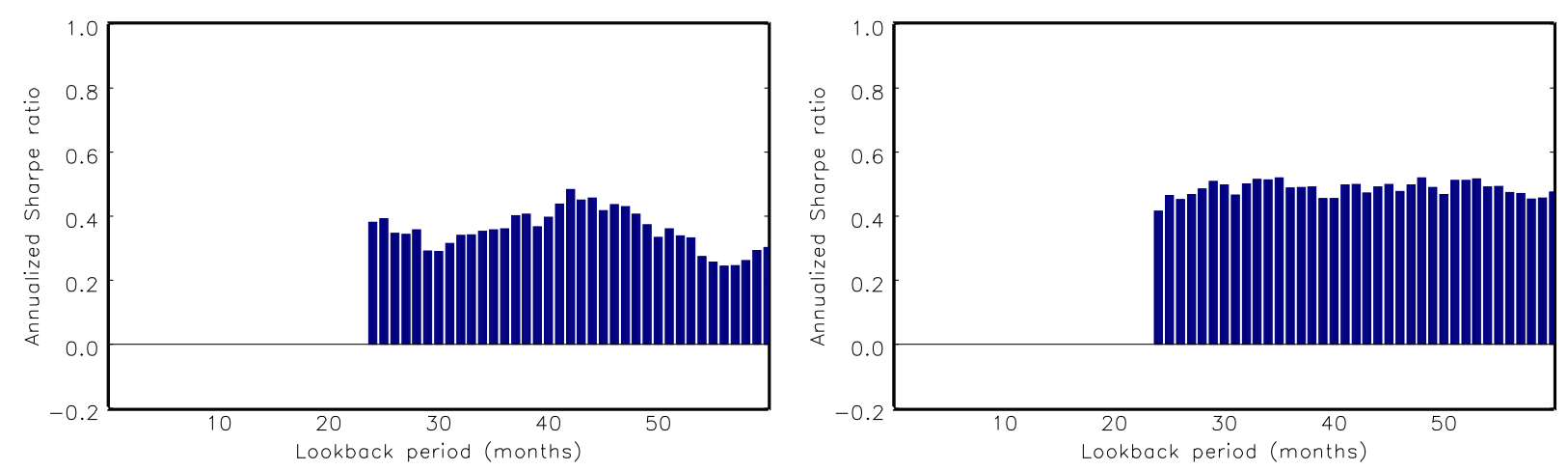

Trade balance
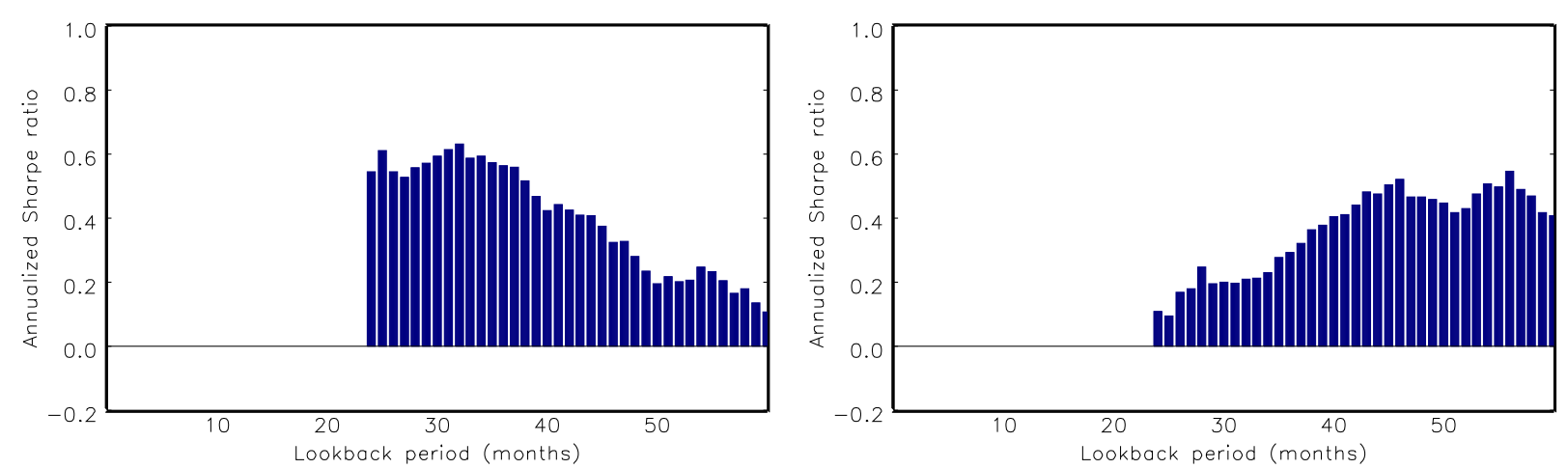

Retail sales
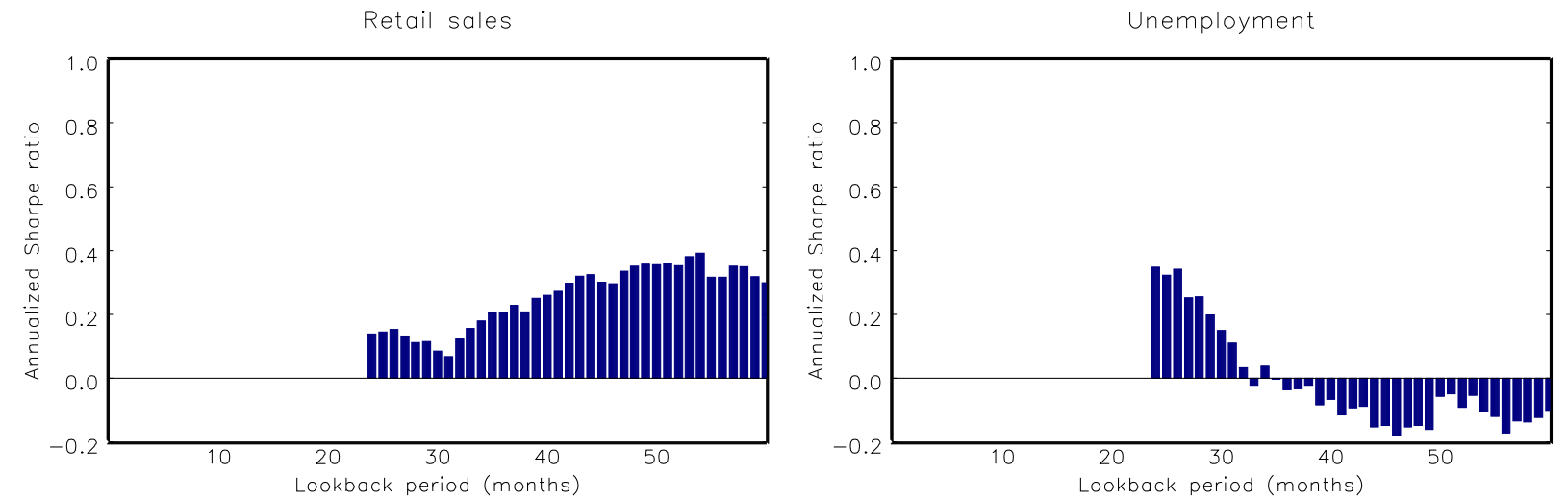

The figure shows annualized Sharpe ratios for fundamental variables versus lookback periods. Each month, each strategy ranks each country according to the strength of past trends in each variable using linear timetrend regressions over a range of lookback periods. Each strategy then uses rank-based portfolio weights and goes long currencies with positive trends and short currencies with negative trends. The inverse of unemployment and flattening of yield spreads are used so that increases in the variables indicate improving economic conditions. The sample period is January 1976 to May 2014. 
Figure 3: Cumulative portfolio returns of trend strategies

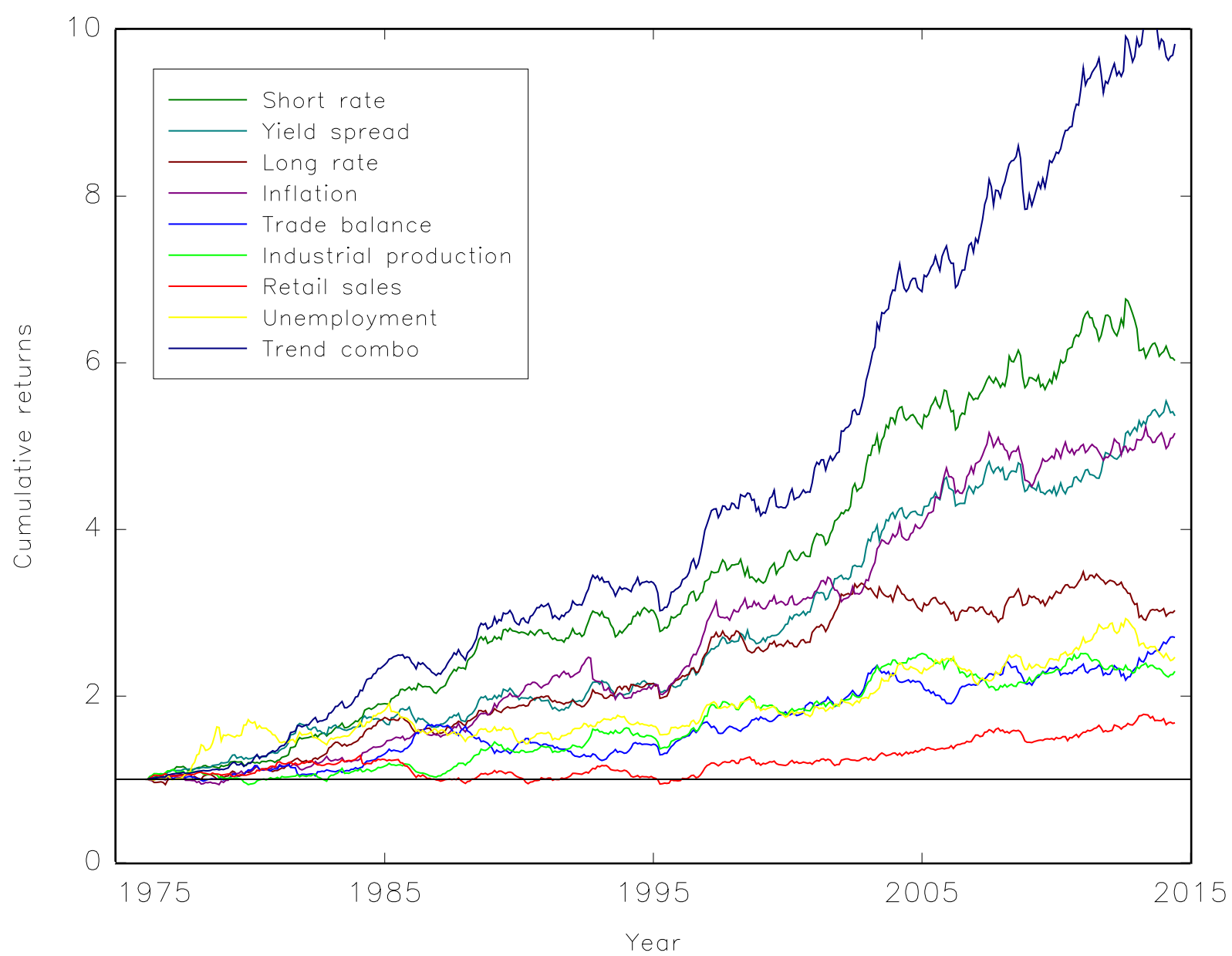

The figure shows the cumulative returns of trend strategies based on fundamental variables. The color scheme is: short rate (green), yield spread (cyan), long rate (red), inflation (magenta), trade balance (light blue), industrial production (light green), retail sales (light cyan), unemployment (light red), and trend combo (blue). The sample period is January 1976 to May 2014. 
Figure 4: Turnover and Sharpe ratios for trend strategies

Turnover

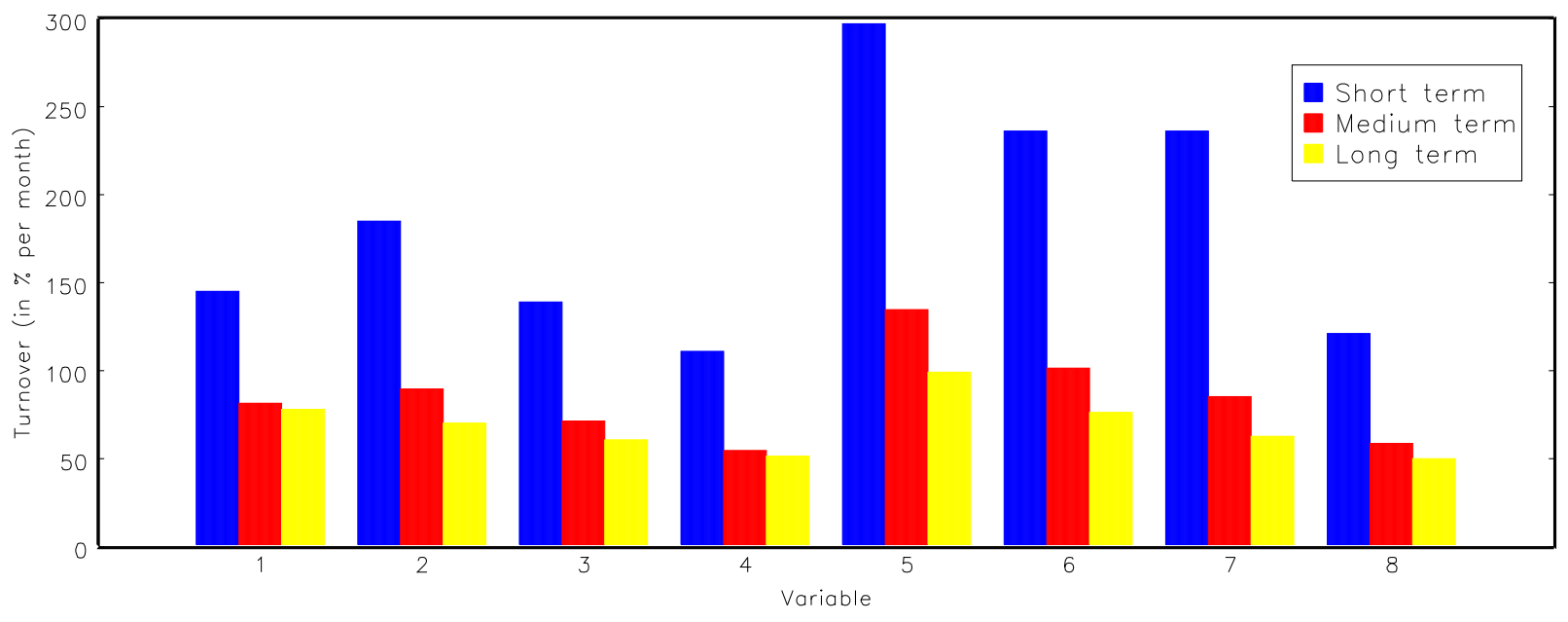

Sharpe ratio (gross)

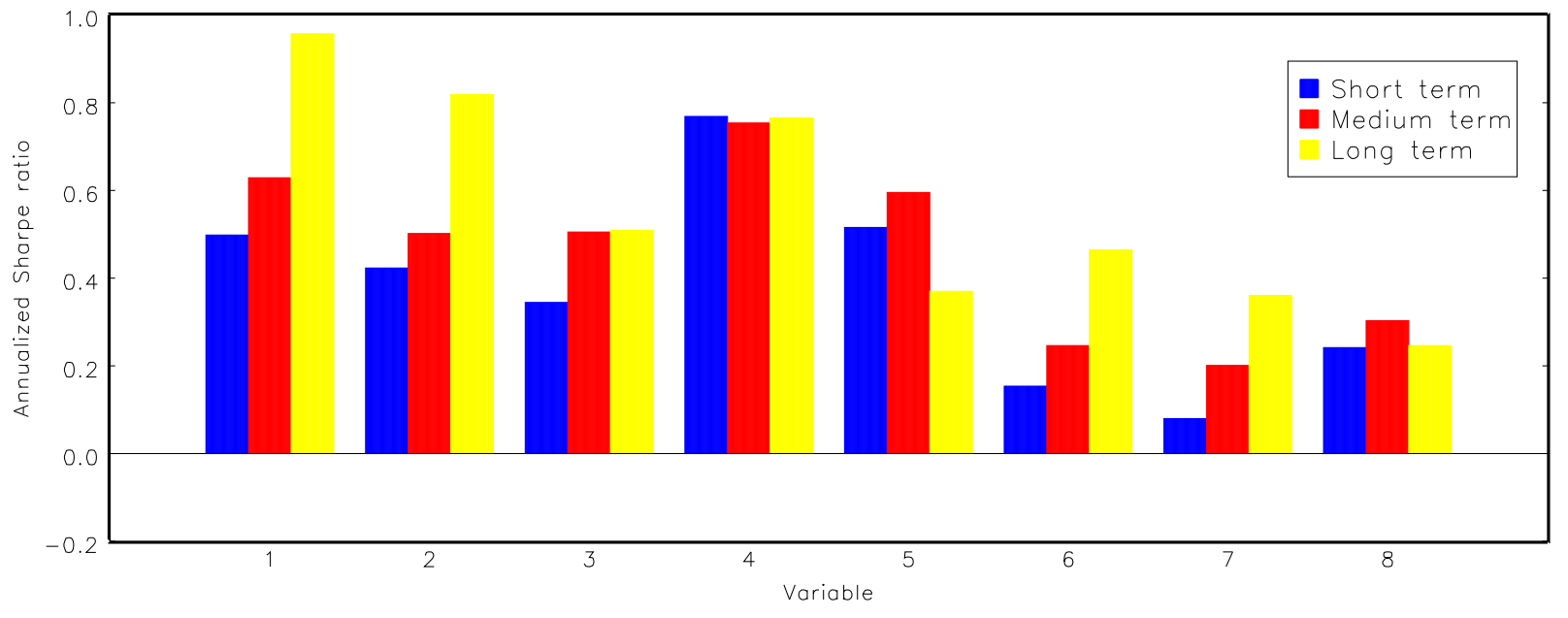

Sharpe ratio (net)

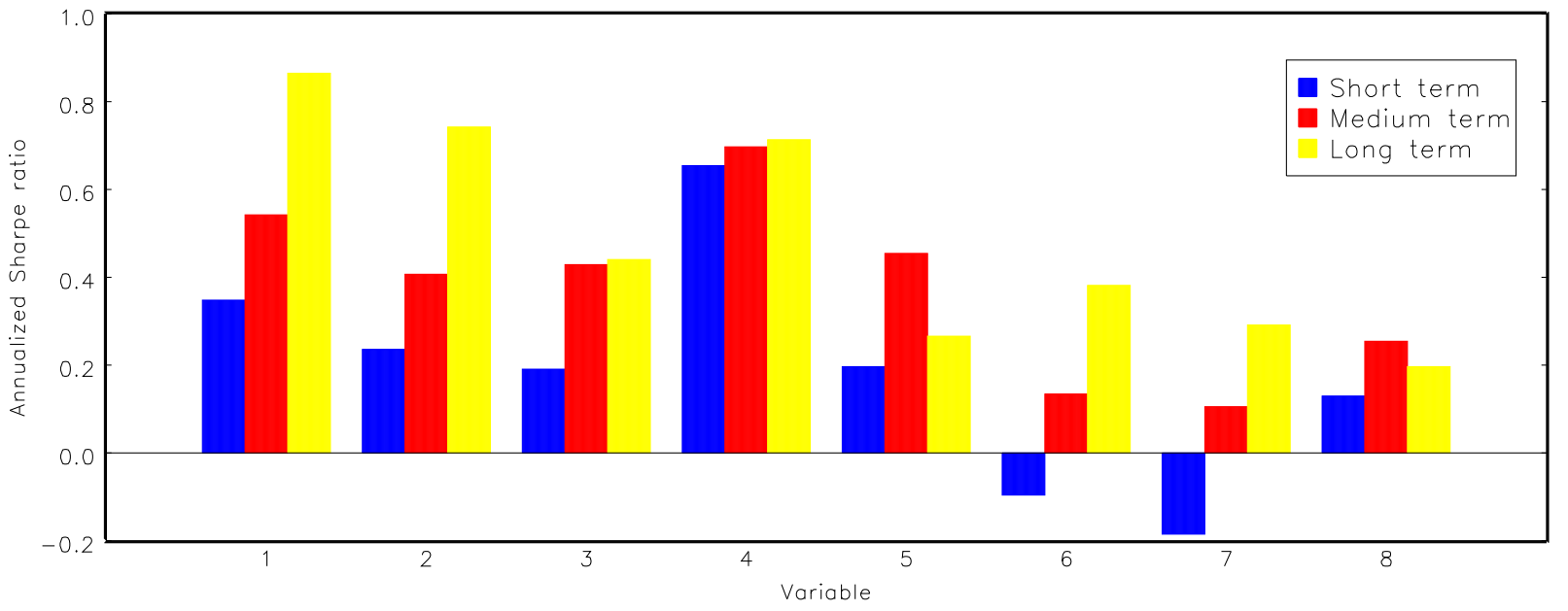

The figure shows average monthly turnover in $\%$ and annualized Sharpe ratios for the variables over the short, medium, and long terms. Sharpe (gross) refers to the Sharpe ratio before transaction costs, while Sharpe (net) refers to the Sharpe ratio after transaction costs, assuming a spread of ten basis points. The variables are: 1. short rate, 2. yield spread, 3. long rate, 4. inflation, 5. trade balance, 6 . industrial production, 7. retail sales, and 8. unemployment. The color scheme of the trends is: short term (blue), medium term (red), and long term (yellow). The sample period is January 1976 to May 2014. 